\title{
GNSS-based analysis of high latitude ionospheric response on a sequence of geomagnetic storms performed with ROTI and a new relative STEC indicator
}

\author{
Rafal Sieradzki*, and Jacek Paziewski \\ University of Warmia and Mazury in Olsztyn, Oczapowskiego 2, 10-719 Olsztyn, Poland
}

Received 5 February 2018 / Accepted 6 January 2019

\begin{abstract}
This contribution presents a combined analysis of the occurrence of polar patches and development of auroral oval triggered by a sequence of geomagnetic storms in March 2012. The detection of the patches was realized with relative slant TEC (STEC) values extracted from geometry-free combination using novel, iterative algorithm of 4-degree polynomial fitting. The proposed approach allows sensing of large structures with high temporal resolution, since it provides epoch-wise information on STEC enhancement in respect to the specified background level. The comparative analysis of the novel indicator with well-known Rate of TEC Index (ROTI) has shown that the new one ensures the more detailed view on patch propagation. The applicability of relative STEC values was also preliminary confirmed by their validation with plasma density data obtained from SWARM mission. The evolution of auroral oval, involving its expansion as well as the intensity of TEC fluctuation, was performed with ROTI parameter. The results of patch occurrence and oval expansion for different geomagnetic conditions are consistent with previous works what proves the feasibility of comprehensive global navigation satellite system (GNSS)-based analyses with the proposed methodology.
\end{abstract}

Keywords: GNSS / polar patches / auroral oval / geomagnetic storm

\section{Introduction}

Throughout the last few decades the measurements with global navigation satellite system (GNSS) signals have become significant and widely used technique in earth sciences. Their application predominantly involves multi-purpose satellite positioning and a broad spectrum of atmospheric studies (Hernández-Pajares et al., 2011; Branzanti et al., 2013; Paziewski, 2015; Wilgan et al., 2015; Banville et al., 2017). Regarding the conditions prevailing in the ionosphere, dual-frequency satellite observations are nowadays commonly applied to total electron content (TEC) mapping (Komjathy et al., 2005; Jakowski et al., 2011; Li et al., 2015; Ren et al., 2016) and monitoring of different-origin ionospheric disturbances (Wautelet \& Warnant, 2014; Park et al., 2013; Ryu et al., 2014; Sieradzki, 2015; Tsagouri \& Belehaki, 2015; Ning \& Tang, 2018).

One of the regions characterized by complicated ionospheric structure is the high geomagnetic latitude area. In this case the occurrence of irregularities is related to the shape of

\footnotetext{
*Corresponding author: rafal. sieradzki@uwm. edu.pl
}

geomagnetic field, allowing the transfer of solar wind energy to the ionosphere-magnetosphere system. As a result of this coupling and complex geophysical processes, the polar and subpolar ionosphere is affected by the occurrence of different phenomena, e.g. patches, polar arcs, auroral oval. The generation and further development of these structures are currently the objects of multi-instrumental studies covering, e.g. their dependence on season or interplanetary magnetic field (IMF) conditions (Bowline et al., 1996; Kullen et al., 2002; Li et al., 2010; Carlson, 2012; Noja et al., 2013; Prikryl et al., 2015a; Spicher et al., 2017). The natural consequence of the connection between the ionosphere-magnetosphere system and the solar wind is also the dependence of the conditions prevailing in the upper parts of atmosphere on space weather events. During such periods, one can observe the intensification of ionospheric structures and equatorward expansion of auroral oval (Kitamura et al., 2012; Horvath \& Lovell, 2014; Cherniak et al., 2015; Sieradzki \& Paziewski, 2016; Durgonics et al., 2017).

At present GNSS-based detection of ionospheric irregularities at high latitudes is performed with two kinds of measurements. First of them is collected by high-rate receivers 
$(50-100 \mathrm{~Hz})$ and allows monitoring of satellite signal scintillations, being a result of the space-based multipath on small-scale disturbances (Forte, 2007). Due to the relatively low number of these instruments, such measurements are typically used to monitor of ionospheric conditions at specific region, e.g. the Canadian High-Arctic Ionospheric Network (Jayachandran et al., 2009). The second dataset is obtained from welldistributed receivers working with standard $30 \mathrm{~s}$ interval. Thus, it is accessible to detect the ionospheric perturbations and their spatio-temporal development (Cherniak \& Zakharenkova, 2017). In this case the ionospheric irregularities are mainly monitored using Rate of TEC Index (ROTI) proposed by Pi et al. (1997). It should be noted that both groups of parameters: $\sigma_{\text {phi, }}$, $S_{4}$ and ROTI, refer to different effects, i.e. signal scintillation or TEC fluctuation, respectively. However, there was observed a strong correlation especially between indices based on phase observations (Pi et al., 2013) and both are currently used for auroral oval characterization.

The aforementioned parameters are computed for short time spans and thus, provide very limited information on large-scale ionospheric phenomena. This is basically a consequence of two factors. The first of them is the generation of small and medium irregularities (from decameter to several tens of $\mathrm{km}$ ) associated with large ones through plasma instabilities (Sojka et al., 1998; Burston et al., 2016; Hosokawa et al., 2016). The second one is high slant TEC (STEC) gradient observed for massive structures, which affects ROTI data. Hence, GNSS-based detection of large structures, such as polar patches, is often performed with TEC maps (Rideout \& Coster 2006; Liu et al., 2010). Although this methodology is generally well-recognized, it has several limitations. One of these is the temporal resolution of maps, which practically determines the feasibility of the dynamic structures detection. Another issue is related to the mapping of STEC to vertical direction. The problem is possible lack of geometrical dependency of STEC on elevation angle, which has been also presented in this work. Thus, the application of incorrect mapping function may lead to strong distortion in TEC maps and consequently deformation of analyzed structures.

In order to overcome the indicated restrictions, this work presents a new approach for detecting large-scale ionospheric structures based on network of permanent stations. In the proposed methodology we use relative STEC values, extracted from time series of geometry-free combination $\left(L_{4}\right)$ data, as an indicator. The signatures of disturbances are isolated from $L_{4}$ observations using iterative algorithm of 4-degree weighted polynomial fitting applied to particular arcs of data. The relative STEC provides the epoch-wise information on ionospheric enhancement or depletion along the signal path propagation with regard to background defined by fitted polynomial. The novel methodology, combined with currently used ROTI parameter, was applied for analysis of the ionospheric response on the string of four geomagnetic storms in March 2012. In specific the relative STEC values were used to investigate polar patches, whereas the second index - ROTI - served as an indicator of auroral oval expansion.

The paper is organized as follows. Section 2 briefly describes geomagnetic conditions during the analyzed period. Subsequently, there is presented an algorithm of relative STEC values determination and dataset used in experiment. Section 4 demonstrates a preliminary comparison of the ionosphere view obtained from the new parameter and ROTI. Section 5 provides validation of new approach with SWARM density data and an attempt of patch definition for GNSS observations. Sections 6 and 7 present the analysis of polar patches and TEC fluctuation performed with relative STEC and ROTI values, respectively. Finally, the summary and conclusions are given.

\section{Interplanetary magnetic field and geomagnetic conditions during the 5-20 March 2012}

The period of March 5-20, 2012 was selected for the GNSSbased analysis of ionospheric conditions. It was characterized by a strong accumulation of space weather events and was a subject of intensive research including Climate And Weather of the Sun-Earth System II (CAWSES) program (Tsurutani et al., 2014; Verkhoglyadova et al., 2014; Gopalswamy et al., 2015; Prikryl et al., 2015b; Belehaki et al., 2017). These contributions describe in detail the geomagnetic conditions in March 2012, thus only a brief description focused on variations of IMF and auroral activity is presented below.

Figure 1 presents an overview of interplanetary and geomagnetic conditions based on OMNI database service (https:// omniweb.gsfc.nasa.gov/). From the top to the bottom it shows 1 min variations of two components of $\mathrm{IMF}(\mathrm{By}, \mathrm{Bz})$ and two geomagnetic indices (AE, SYM-H). The epochs with minimal SYM-H and interplanetary (IP) shocks, identified in Advanced Composition Explorer (ACE) spacecraft data by Tsurutani et al. (2014), are denoted with purple solid and dashed lines, respectively. Treating $-50 \mathrm{nT}$ value of SYM-H index as a starting level of storm one can identify four events occurring on March 7, 9, 12 and 15, respectively. For the unification purpose with previous works they are called from S1 to S4 hereafter.

The $S 1$ event was a typical geomagnetic storm with a negative IMF $\mathrm{Bz}$ before the IP shock. The transfer of solar wind energy to the magnetosphere through magnetic reconnection is considered as a cause of storm. After the interplanetary shock, there was observed a rapid decrease of SYM-H index to the minimum equal to $-98 \mathrm{nT}$. Simultaneously, the intensified auroral activity was started to register. It can be divided into two periods with negative IMF Bz, i.e. the first at the peak of SYM-H (with AE index $1300 \mathrm{nT}$ ) and the second $\sim 8 \mathrm{~h}$ later $(1750 \mathrm{nT})$. Another south-to-north change of IMF Bz (22:00 UT) terminated the auroral activity, which remained at low levels by the IP shock of the second storm. S2 event was initiated during northward IMF by the sudden positive impulse causing rapid growth of SYM-H to $54 \mathrm{nT}$. In the following the following hours $\mathrm{By}$ and $\mathrm{Bz}$ changed their orientation several times. Interestingly, although IMF conditions were dynamic, AE index increased by degrees up to $1200 \mathrm{nT}$. The north-south change of Bz polarity ( 2:20 UT, 9 March) led to development of geomagnetic storm with minimum of SYM-H at the level $-148 \mathrm{nT}$. During S2 storm the values of $\mathrm{AE}$ index were maximal in the entire analysed period and exceeded $2500 \mathrm{nT}$. The third geomagnetic storm was preceded by two IP shocks. The first of them caused only the moderate changes of magnetic field and was followed by slow decrease of SYM-H values up 


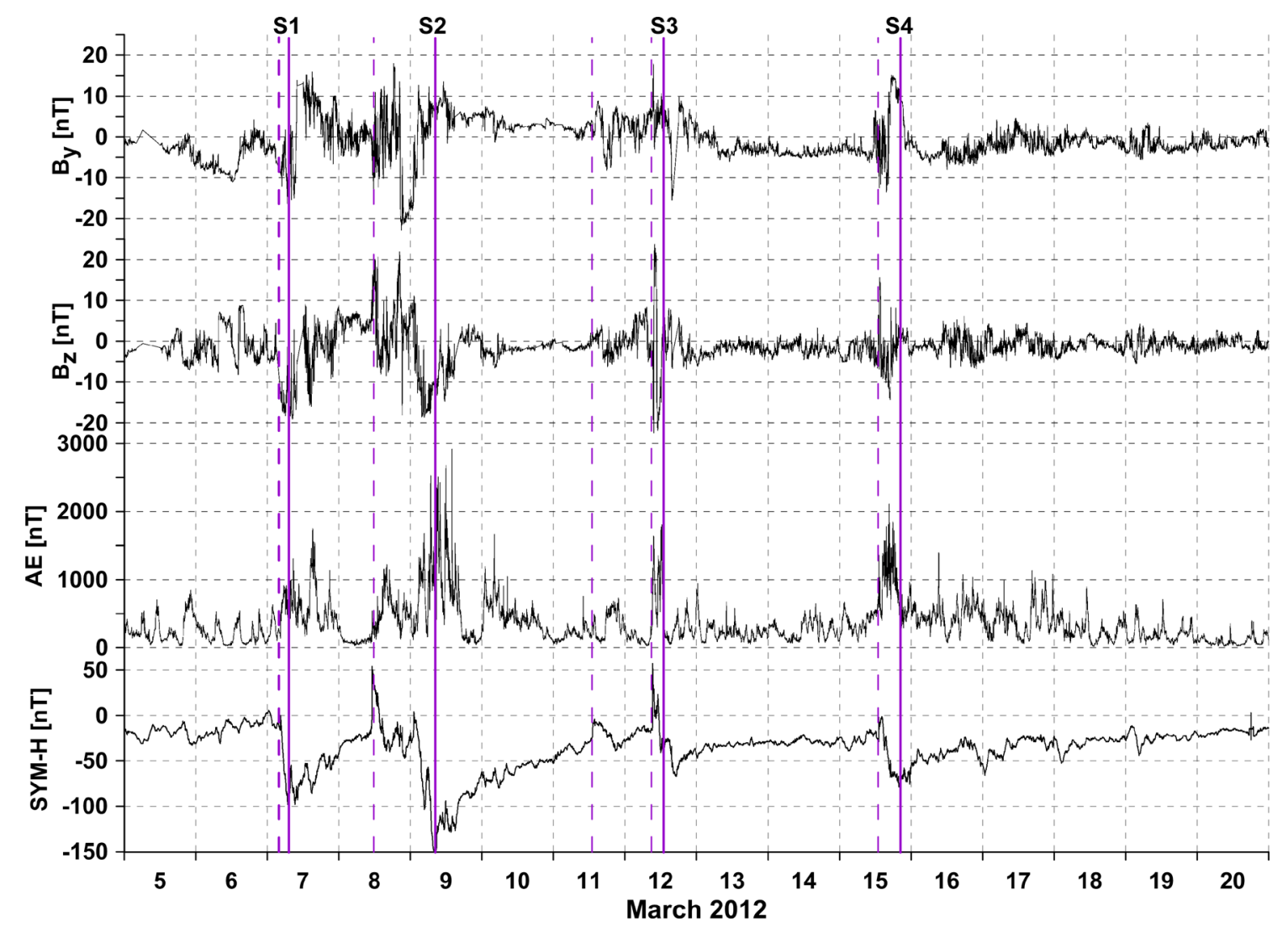

Fig. 1. The variations of the interplanetary magnetic field (By, Bz) and geomagnetic parameters (AE, SYM-H) during March 5-20, 2012. IP shocks and minima of SYM-H index for S1-S4 are marked with dashed and solid purple lines, respectively. The peak of the third storm is shifted according to Tsurutani et al. (2014).

to $-40 \mathrm{nT}$, whereas the second one initiated the main phase of S3 event. The correction of SYM-H index for solar wind ram pressure introduced by Tsurutani et al. (2014) revealed that the peak of SYM-H $(-75 \mathrm{nT})$ occurred at $\sim 12: 00$ UT and thus such epoch was adopted in Figure 1. Taking this into account the intense auroral activity is detected only during the main phase of S3. Similar situation one can observe during the last storm. After the IP shock, IMF Bz progressively dipped to $-15 \mathrm{nT}$, what resulted in a rapid decrease of SYM-H. The peak of the storm was characterized by SYM-H equal to $-79 \mathrm{nT}$. This event was affected by high speed stream, which caused the extended recovery phase with increased auroral activity (Verkhoglyadova et al., 2014).

\section{Methodology and dataset}

In this contribution we propose to use the relative changes of $L_{4}$ combination in order to improve the current GNSSbased methods of ionospheric research. The idea to take advantage of such data for disturbances detection has been already applied to describe many ionospheric structures, including polar patches as well (Noja et al., 2013; Jin et al., 2014). However, due to the unique ambiguity term for each observational arc, $L_{4}$ time series were usually presented separately for specific satellite. This work demonstrates the algorithm of combined processing of such observations collected by a network of permanent GNSS receivers, which can be considered as the main novelty.

The applied methodology of $L_{4}$ time series processing consists of a few steps. The starting point of algorithm is the detection and repair of phase cycle-slips, which frequently occur at high latitudes (Astafyeva et al., 2014; Prikryl et al., 2014). In order to retrieve the clean $L_{4}$ series, the modified approach proposed by Liu (2011) is adopted. Its basis is the approximated ROT value at epoch $k$ computed using data from previous epochs:

$$
\operatorname{ROT}_{(k)} \approx \operatorname{ROT}_{(k-1)}+\operatorname{RÖT}_{(k-1)} \cdot \Delta t
$$

where:

$$
\begin{gathered}
\operatorname{ROT}_{(k-1)}=\frac{L_{4(k-1)}-L_{4(k-2)}}{\Delta t}, \\
\operatorname{ROT}_{(k-1)}=\frac{\operatorname{ROT}_{(k-1)}-\operatorname{ROT}_{(k-2)}}{\Delta t} .
\end{gathered}
$$


The cycle-slips detection and repair are realized using the difference of approximated $\mathrm{ROT}_{(k)}$ with a real one, computed at epoch $k$ directly from equation (2), and a selected threshold. In our case this limit was set to 6 TECU/min (TECU - unit defined as $10^{16}$ electrons per $\mathrm{m}^{2}$ ). Such loosely constrained boundary is implicated by the high dynamics of TEC during geomagnetic storms (Sieradzki et al., 2013; Cherniak \& Zakharenkova, 2017). Due to the same reason $\mathrm{ROT}_{(k-1)}$ and $\mathrm{ROT}_{(k-1)}$ values in equations (2) and (3) were calculated as an average over 5 previous epochs. In the case of presence of cycle-slip at epoch $k$, the consecutive $L_{4}$ values in the particular arc are corrected by a subtraction of difference between real change of geometry-free combination and $\mathrm{ROT}_{(k)}$ computed using equation (1). Such approach allows epoch by epoch elimination of all cycle-slips assuming their lack in the first few epochs.

After the outlier detection the observations for each arc have to be detrended to extract the signatures of ionospheric disturbances. For this purpose we propose to use weighted 4th order polynomial fitting applied to clean $L_{4}$ data. However, due to the extreme positive effects related to, e.g. the polar cap patches, the fitting is implemented in different way depending on detected TEC variations. The process is performed for each arc via three-step procedure:

1. The levelling of clean $L_{4}$ time series in order to set their minimal values to 0.2 .

2. Preliminary fitting of polynomial with unit weights.

3. If the maximal difference between $L_{4}$ values and fitted polynomial is lower than $5 \mathrm{TECU}$, these results are treated as final. In the opposite case, the polynomial coefficients are estimated in two-steps iterative mode removing epochs with differences higher than 3 TECU. These repetitions are performed with weights equal to $1 / L_{4}$.

The first step is linked with iterative fitting (step 3) and allows the faster tuning the polynomial to variations related only to daily changes of TEC and the impact of elevation angle (background STEC level) through suitable weights. If STEC fluctuation is low, it can be assumed that the initial fitting (step 2) corresponds to the background level. In the opposite case, the final 2-steps iterative mode is responsible for its fast approximation. The applied thresholds were selected empirically to be effected for polar patch detection.

The initial elevation mask is set to $10^{\circ}$ in order to stabilize the fitting. Due to the discontinuous data at low elevation the clean time series typically start at about $10-15^{\circ}$. Moreover, we employed only data arcs longer than $3 \mathrm{~h}$. As shown in our tests, this temporal limit is much higher than periods of enhanced STEC, being a consequence of patch propagation. This fact rather prevents the structure (or their sequence) from filling the entire arc and we did not observe such effect in our dataset. Another issue, which can distort the fitting, is the occurrence of structures at the edges of arc (partially outside). The time series derived for particular arcs indicated that this effect for extended structures may deform the background level at low elevations (mostly below $25^{\circ}$ ). The elimination of this defect was realized by setting the elevation mask to $30^{\circ}$ in final multi-station solution.

Figure 2 demonstrates the performance of algorithm applied for observations of the satellites GPS 11 (station ALRT) and

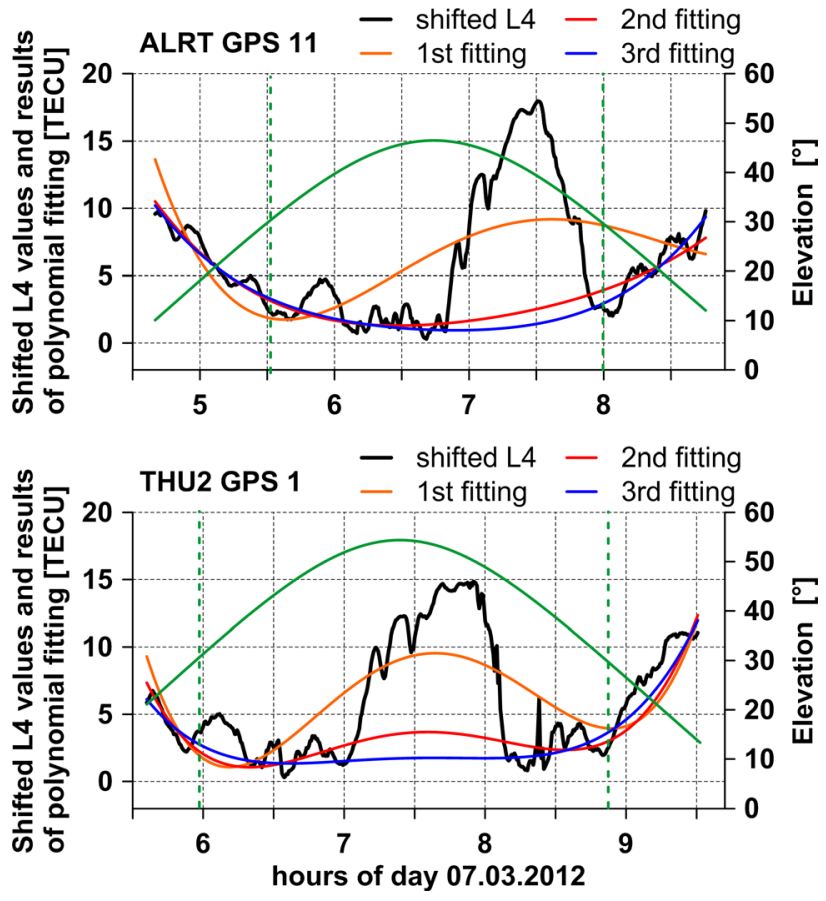

Fig. 2. Background TEC estimation using iterative polynomial fitting for satellite GPS 11, station ALRT (top panel) and satellite GPS 1, station THU2 (bottom panel). Green line corresponds to elevation of satellites and applied cut-off angle $\left(30^{\circ}\right)$.

GPS 1 (station THU2). It presents the results of fitting for an extreme structure, classified as tongue of ionization (TOI), which occurred during S1 event. The final polynomial can be treated as an approximation of background STEC level. Thus, the difference between $L_{4}$ time series and fitted function, called in this study relative STEC, results in an extraction of ionospheric signature. The small negative values, which are a natural consequence of applied approach, do not usually exceed 2 TECU for disturbed ionosphere.

The new indicator - relative STEC - can be theoretically converted to VTEC using any mapping function but this step is not suitable in the case of the large polar phenomena (Fig. 3). The results given for ALRT and THU2 stations show that variations of STEC are practically the same for two analysed satellites (GPS 1 and GPS 11) despite the difference in elevation reaching even up to $20^{\circ}$. For the GPS 32 satellite, which was characterized by different orientation, the initial part of ionospheric structure is observed with $\sim 15$ min delay. Nevertheless, the maximal growth of STEC is very close to these detected for GPS 1 and 11. Figure 3 also depicts that algorithm works correctly for low-elevated data. The similar analysis for other structures confirms the independence of relative STEC values on elevation angle and thus one can assume that the application of STEC-VTEC conversion would cause the distortion of results. As a consequence we decided to use the relative STEC values in the following analyses.

The second parameter used in this study was ROTI, which is defined as a standard deviation of ROT data (2) computed in 5 -minute interval. While it is considered to be effective in 

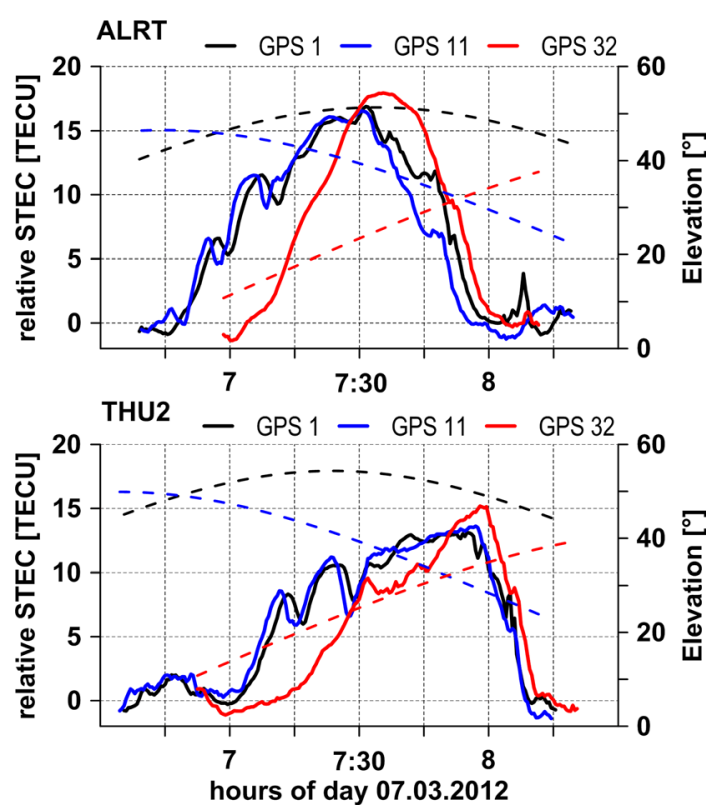

Fig. 3. Signatures of TOI observed for satellites at different elevations: station ALRT (top panel) and station THU2 (bottom panel).

describing of auroral activity, its main disadvantage is providing the information only on the level of temporal STEC variations. In this study ROTI values were computed on the basis of preprocessed relative STEC time series instead of raw observations. As a result, the outliers, being an effect of cycle-slips, were removed.

The presented tests were performed with multi-GNSS (GPS + GLONASS) data obtained from 180 permanent receivers located at the northern high-latitudes (Fig. 4). The selected stations belong mostly to International GNSS Service (IGS), EUREF Permanent Network (EPN) or participate in Plate Boundary Observatory (PBO) mission. Despite the inhomogeneous distribution of receivers, which is related to their low number for selected areas and land mass configuration, this coverage allows the detection of individual ionospheric structures and their convection.

\section{Preliminary comparison of ionospheric disturbances depiction with ROTI and relative STEC values}

The first goal of this work is the comparison of ROTI and relative STEC values as indicators of irregularities occurrence. The former is well-recognized as indicator of small and medium disturbances, while the new one is expected to provide information on all-scale phenomena identifiable with 30 s resolution of data. Due to the overlapping of both ranges, the expected upper boundary of structure detectable with ROTI should be defined. Such approximation can be derived by multiplying velocity plasma drift equal to $600-700 \mathrm{~m} \mathrm{~s}^{-1}$ (Grant et al., 1995) and 5-minute period. This assumption neglects the move of

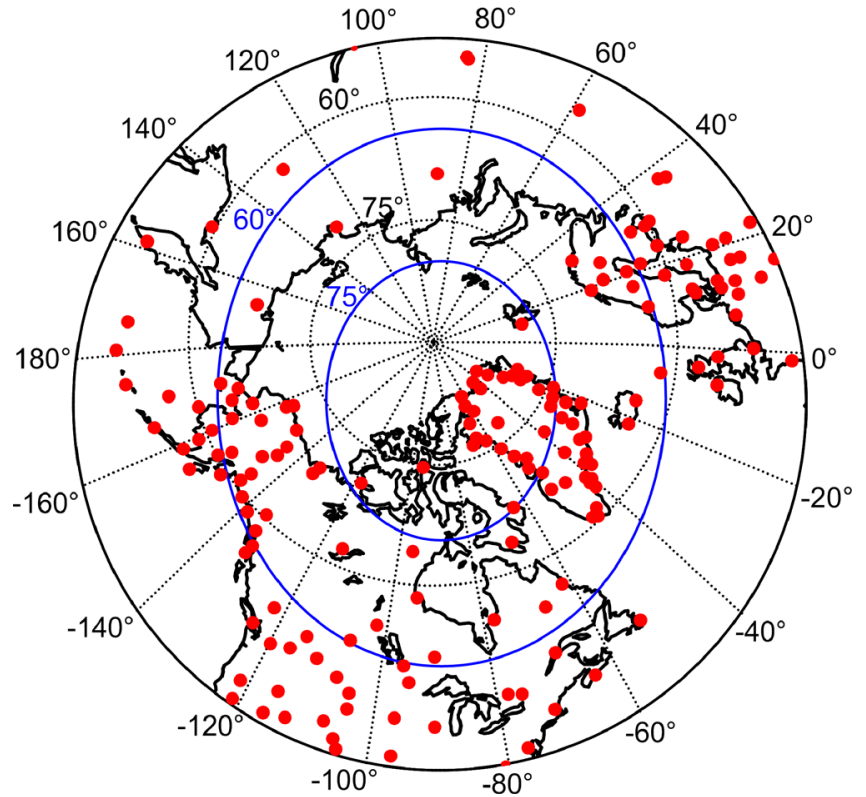

Fig. 4. Distribution of GNSS permanent stations employed in experiment. The altitude-adjusted corrected geomagnetic latitudes (blue lines) are superposed over the geographic grid.

Ionospheric Piercing Point (IPP). Thus, ROTI should be effective for ionospheric irregularities with size up to $200 \mathrm{~km}$, what theoretically involves small patches $(100-200 \mathrm{~km})$ as well. In the case of the larger structures the enhanced values of this parameter are mostly related to the coexistence of patches and smaller irregularities or high STEC gradients. Analysing the impact of time resolution on new parameter, it is fully efficient for structures larger than several tens of kilometers. It should be noted that the applied cycle-slip threshold limit (6 TECU/min) eliminates the sharp, short-term peaks of $L_{4}$ (independent on their origin). This step automatically defines the minimal size of structure with such enhancement at the level of $\sim 100 \mathrm{~km}$.

In order to highlight the difference between both parameters we selected three arcs with large structures clearly observed in relative STEC values (Fig. 5). Due to the different time interval used for relative STEC and ROTI values, the latter parameter was in this case computed using moving window and referred to the middle epoch. In the top panel of Figure 5 high ROTI values, exceeding $1 \mathrm{TECU} / \mathrm{min}$, are observed mainly at the edges of large structure what corresponds well with previous investigations (Mitchell et al., 2005; Van der Meeren et al., 2014). The effect observed in ROTI is mostly related to co-existence of smaller-scale irregularities, nevertheless, one can assume that indicates the occurrence of large structure as well. The second example, showing the same structure (Fig. 5, middle panel), depicts more ambiguous case. Here the high ROTI values (0.8-0.9 TECU) are derived for the large structure as well as for smaller ones and consequently the identification of the former is rather not applicable. The comparison of two first panels demonstrates that effectiveness of ROTI depends on individual case. The lower ROTI values for large 

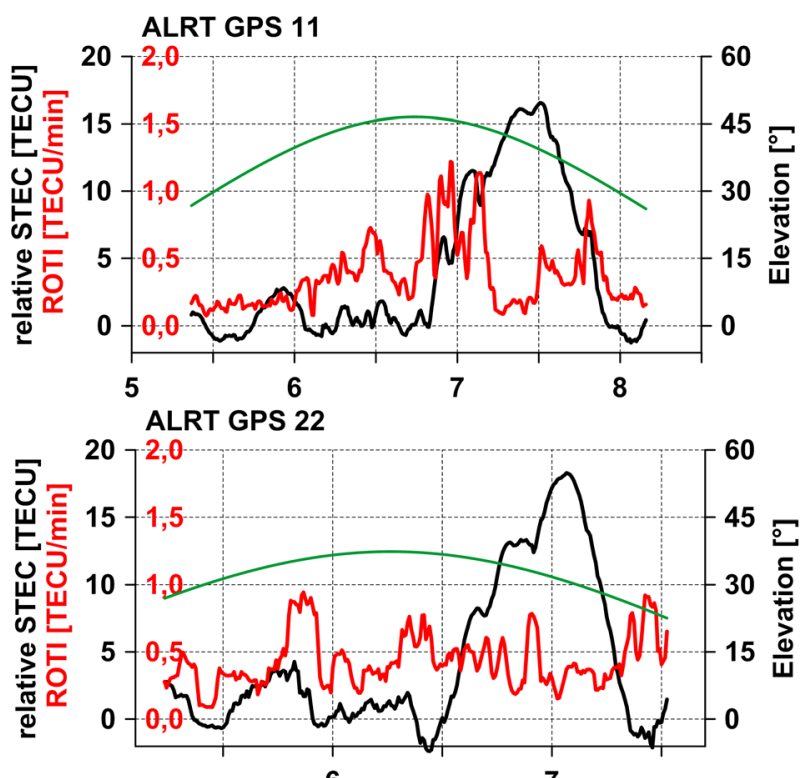

ALRT GPS 3

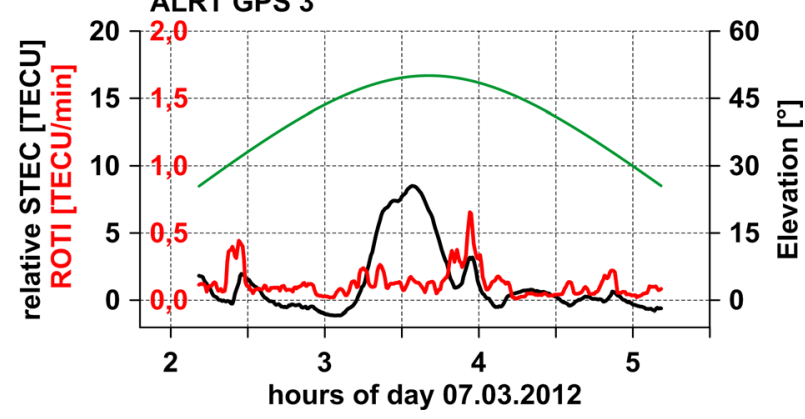

Fig. 5. Relative STEC and ROTI values for three arcs of ALRT data: satellite 11 (top panel), satellite 22 (middle panel) and satellite 3 (bottom panel), respectively.

structure in the middle panel seem to be related to the difference in elevation mask and smoothness of relative STEC time series. The last graph (Fig. 5, bottom panel) shows the large structure characterized by a smooth signature, which results in a very low ROTI values - below 0.3 TECU. In such extreme case ROTI is completely useless and does not provide any information on observed phenomena. Looking at the other disturbances in these arcs we can observe the high enhancement of ROTI for smaller irregularities. It should be noted that the time series of the new parameter, given in Figure 5, indicate its applicability also for weaker structures. In such case the key factor seems to be an accurate definition of background STEC level.

The difference between ROTI and relative STEC is also transparent in multi-station results showing the development of ionospheric disturbances during S1 event (Fig. 6). The top panel (Fig. 6a and b) depicts 2-hour point maps of ROTI and relative STEC values as a function of magnetic local time (MLT) and altitude-adjusted corrected geomagnetic (AACGM) latitude for period of 8:00-10:00 UT, March 7, 2012. The bottom panel provides information on temporal variations of TEC during the entire day. It presents the ionospheric observations satisfying the conditions: $0 \pm 3 \mathrm{~h}$ and $12 \pm 3 \mathrm{~h}$ of MLT

below $80^{\circ}$ of AACGM latitude and all observations above this latitudinal threshold limit. This distinction was caused by a small spatial extent of sectors near the geomagnetic pole and resulted in a larger number of samples available there. In this latter case (above $80^{\circ}$ ) the points were preliminarily projected on noon-midnight axis and then the latitudes of such data were used to prepare Figure $6 \mathrm{c}$ and d. The ROTI and relative STEC were computed for all stations given in Figure 4 with the application of the elevation mask equal to $30^{\circ}$. Subsequently, they were converted to MLT-AACGM latitude reference frame using ionosphere single layer model with height adopted at $350 \mathrm{~km}$. AACGM coordinates were computed according to methodology proposed by Shepherd (2014).

ROTI map given in Figure 6a provides pronounced signature of auroral oval (denoted as \#1) with outer boundary at $65^{\circ}$ and $55^{\circ}$ of AACGM latitudes on day- and night side, respectively. Furthermore, one can also observe the TOI/patch structures (\#2), what confirms that under favourable conditions they can be detected with ROTI. On the other hand the results of TEC fluctuation for auroral oval and large structures are at the similar level, $2 \mathrm{TECU} / \mathrm{min}$, what makes it difficult to separate both effects. The corresponding results for new parameter emphasize the TOI/patch structures characterized by STEC enhancement exceeding 20 TECU (Fig. 6b). They also reveal the fragments of storm enhanced density (SED) plume (\#3) transported from mid-latitude post-noon sector to dayside auroral oval. Despite the low number of observations for this area, its signature can be observed from about $58^{\circ}(\sim 18 \mathrm{MLT})$ to $67^{\circ}(\sim 12 \mathrm{MLT})$ of AACGM latitude. The relative STEC enhancement for SED reached up to 15 TECU. With regard to auroral oval, the mean values of relative STEC did not exceed 4-6 TECU and are much lower than these observed for large phenomena. This is important advantage of new indicator, which allows the separation of both effects. It is also worth to notice that the proposed methodology exposes the trace of ionospheric through (\#4), which is observed at the post-midnight hours and characterized by TEC depletion up to 4 TECU.

The bottom panel of Figure 6, presenting variations of both parameters along noon-midnight axis, confirms the difference in highlighted ionospheric effects. Since ROTI maps enable to follow variations of auroral oval (Cherniak et al., 2015; Sieradzki \& Paziewski 2016), Figure 6c depicts its dynamic expansion during the particular phases of S1 storm. The comparison of ROTI and relative STEC results justifies that the former index is more suitable to follow auroral oval boundaries and strong TEC fluctuation at the cusp (\#5). The second visible effect is the growth of ionospheric variability associated with the $\mathrm{TOI} /$ patch propagation. However, these results are ambiguous, i.e. between 8:00 and 12:00 UT seem to correlate well with relative STEC values, but for the strongest TOI structure and other less pronounced structures this agreement is rather poor. It basically confirms the results given in Figure 5.

The temporal variations of relative STEC values for noonmidnight axis are oriented on TOI/patch detection (Fig. 6d). As it can be observed the convection of these structures, characterized by different STEC enhancement, occurred practically for entire day. Apart from the strongest phenomena (6:00-11:00 UT), the smaller-amplitude effects (up to 10 TECU) were detected before the storm and during its recovery phase. It suggests that the transport of ionized plasma across the polar 


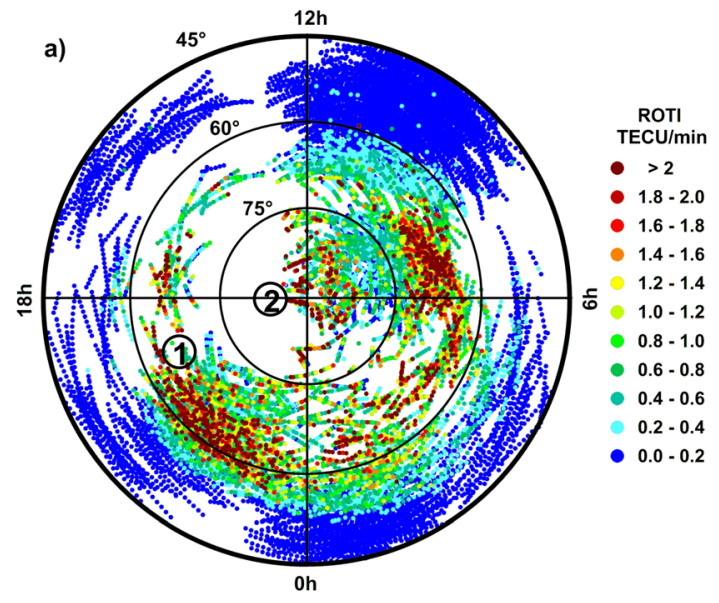

8:00-10.00 UTC, 7.3.2012

c)

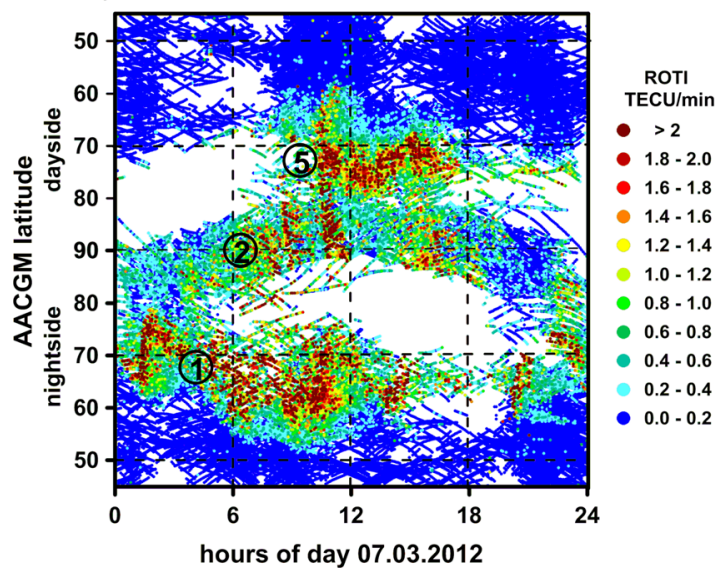

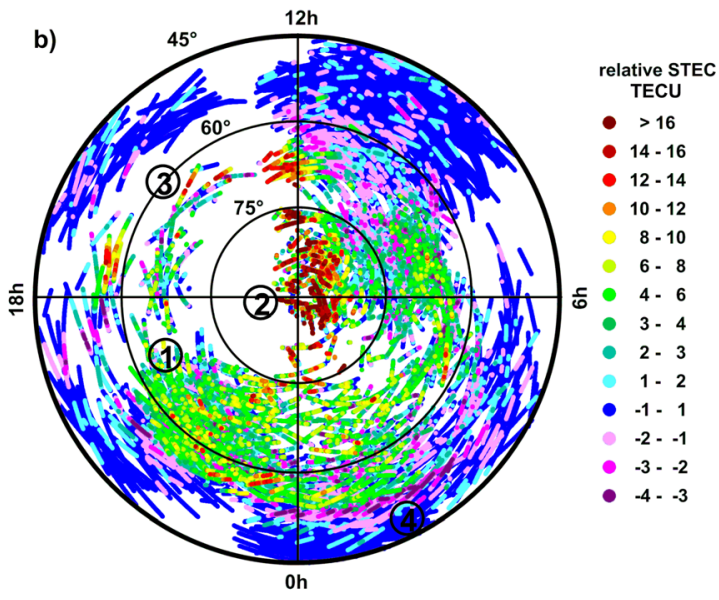

8:00-10.00 UTC, 7.3.2012

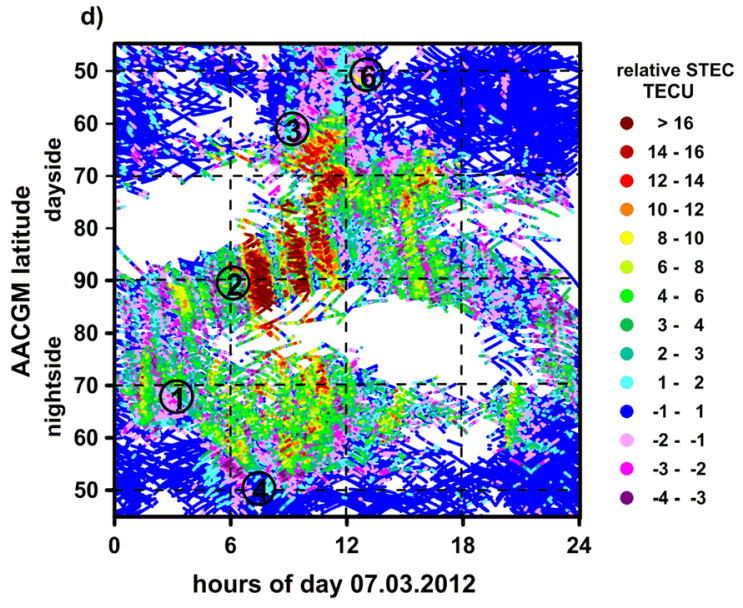

Fig. 6. The comparison of ROTI (left panel) and relative STEC (right panel) values. Top panel: 2-hour point maps (8:00-10:00 UT, 7 March 2012) of ionosphere presented as a function of AACGM and MLT. Bottom panel: temporal changes of both parameters observed on day- and night-side ionosphere on 7 March 2012. 1 - auroral oval, 2 - TOI/polar patch, 3 - SED, 4 - ionospheric through, 5 - cusp, 6 - LSTID.

cap in favourable circumstances is practically continuous. Looking at Figure 6d one can also observe plume of SED, occurring on the day-side at $65^{\circ}(\sim 9: 30$ UT). Its occurrence seems to be an effect of the rapid IMF variations (Fig. 1), which detached polar cap structures from SED reservoir. Figure 6d depicts also the signature of ionospheric through denoted as negative STEC values at the outer boundary of night-side oval (6:00-10:00 UT). Moreover, on the day-side one can observe the equatorward development of Large Scale Travelling Ionospheric Disturbances (LSTID) initiated with $\sim 2$ hour delay with respect to the storm (\#6). The occurrence of these irregularities on March 7, 2012 was reported and analyzed by Belehaki et al. (2017). With regard to relative STEC the scale of this effect is rather low (from -2 to 2 TECU), but it was observed for all analyzed events. Finally, on the basis of results given in Figure $6 \mathrm{~b}$ and $\mathrm{d}$, it can be concluded that at midlatitudes (quiet ionosphere) a typical difference between final polynomial and raw $L_{4}$ data does not exceed \pm 1 TECU. This fact validates the fourth-order polynomial as an approximation of $L_{4}$ variations associated with daily changes of TEC and elevation angle.

\section{Validation of relative STEC values with SWARM measurements}

The application of new indicator has to be preceded by its validation and definition of polar patch for GNSS data. In order to achieve both these goals we used the result of Polar Cap Products (PCP) project founded by European Space Agency and handled by Department of Physics, University of Oslo (https://www.mn.uio.no/fysikk/english/research/projects/swarm/). The main objective of the project was an automatic detection of polar patches using density data derived from SWARM mission. The basis of algorithm used there is well-known definition of patch as an enhancement of plasma density by a factor of two (Crowley, 1996). Thus, the identification of such structures relied on the assessment of ratio between foreground and background density plasma, which in turn were derived using percentile filtering technique of raw data (Spicher et al., 2017).

Since SWARM dataset does not cover 2012, we selected the period of 18-27 October 2014. It was characterized by a good 


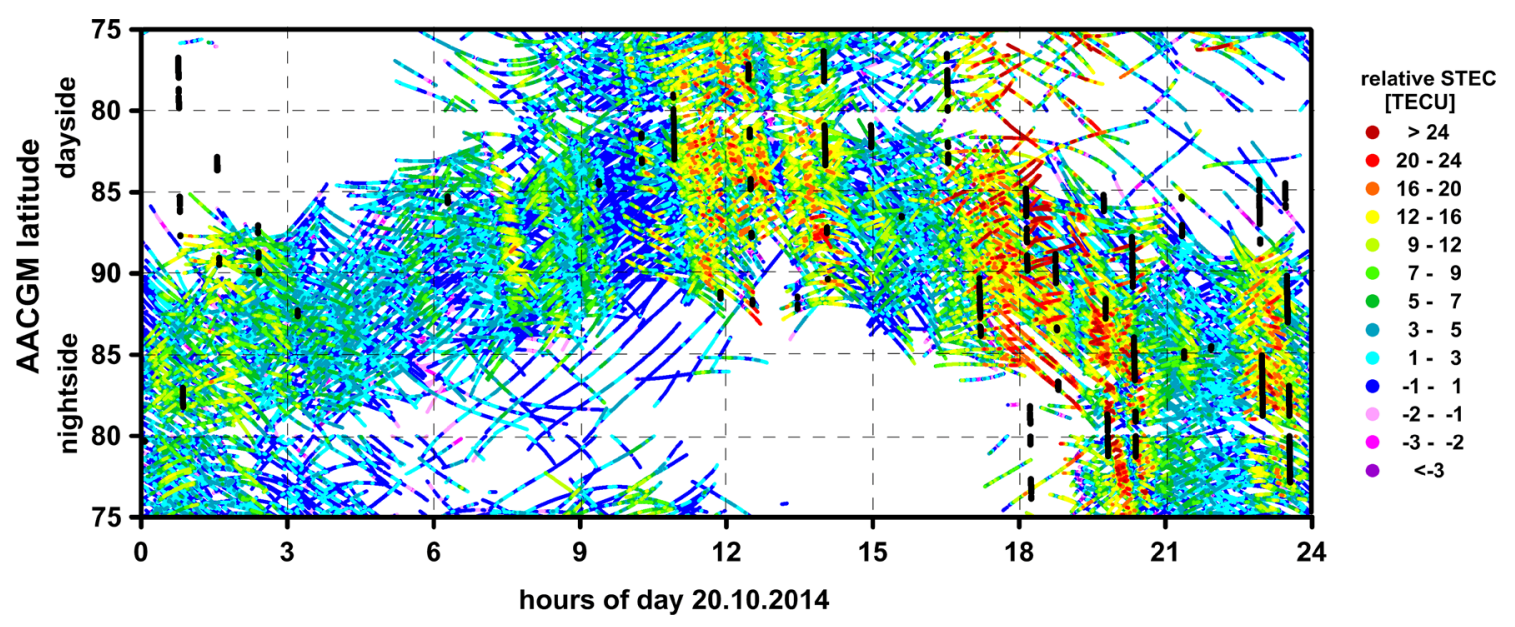

Fig. 7. The temporal changes of relative STEC values observed on day- and night-side ionosphere on 20 October 2014. Black dots correspond to results of PCP project with foreground/background density ratio higher than 2 .

collocation of both techniques measurements and about 20 structures per day detected by SWARM satellites. Figure 7 presents an example of combined results of relative STEC values and PCP project for 20 October 2014. It was generated the same as Figure 6d, but the SWARM measurements with foreground/ background density ratio higher than 2 (black dots) were superposed on relative STEC values. Discontinuities observed at $80^{\circ}$ of AACGM latitude are a consequence of the applied algorithm.

We generally observe a good coincidence between both methods, i.e. the patches detected using SWARM mission data correspond to high values of relative STEC. Comparing the intervals with high patch activity only, this agreement is even very well, with one exception ( 7:00-9:00 UT). In this case, however, the entire traces of SWARM arcs were below $82^{\circ}$ of AACGM latitude and intersected the polar cap area only for post-noon sector. As a result the structures depicted in relative STEC could not be detected by SWARM satellites. The second effect observed in Figure 7 is the occasional occurrence of short time shift between both methods, for example at 11:00 UT. Its reasons can be twofold: the high difference between SWARM velocity and GNSS IPP change $\left(\sim 7.5 \mathrm{~km} \mathrm{~s}^{-1}\right.$ and usually below $100 \mathrm{~m} \mathrm{~s}^{-1}$, respectively) and projection of latitudes to noon-midnight axis above $80^{\circ}$ applied for visualization purpose. Both these issues may lead to such time shift when SWARM data are close to areas covered by GNSS data, but do not intersect them.

The last step required for further investigations of polar patches is the definition of such structure in relation to ground-based measurements. It is clear that the common definition used for the in-situ data (foreground/background ratio > 2) cannot be applied. Moreover, although such observations were used for patch detection (Krankowski et al., 2006; Durgonics et al., 2017), the appropriate definition was not assessed. The only work considering this issue is analysis of patch occurrence based on CHAMP GNSS data, which termed this structure with mixed absolute and relative criteria (Noja et al., 2013). Since the definition for space-borne measurements cannot be simply adopted as well, we decided to assess the patch enhancement comparing SWARM density ratio and measurements from ALRT station (its localization near the pole guaranties the most transparent patch structures). For this purpose we used the combined results from validation period (18-27 October 2014). The indicator employed for GNSS data can be described as following ratio:

$$
\text { GNSS ratio }=\frac{\text { relative STEC }+ \text { VTEC }}{\text { VTEC }},
$$

where relative STEC values are results of our algorithm and VTEC, representing background level, is adopted from Global Ionosphere Maps (GIM). VTEC values can be replaced by STEC but the definition in this form is correct, assuming the independence of STEC enhancement on elevation angle (see Sect. 3), and more transparent. In this work VTEC values for each IPP are linearly interpolated from hourly GIMs provided by European Space Operations Center (ESOC) (Feltens, 2007). Taking into account the time resolution of this product and its base function (spherical harmonic expansion), the impact of patch occurrence on ESOC maps is expected to be low. As a result such VTEC values should be a good approximation of the background level.

Due to the different dynamics of geometry for both techniques, the searching of the same structures in both datasets is not a trivial task. The initial step was finding the collocated observations of SWARM (with density ratio > 2) and GNSS. In this work we applied thresholds equal to $15 \mathrm{~s}$ and $200 \mathrm{~km}$ in time and distance domains, respectively. Then, as SWARM density ratio for particular structure the maximal one was adopted, whereas in GNSS data we searched the peak of STEC within the range $\pm 10 \mathrm{~min}$ from epoch of the collocated data. For further study we selected only clearly identified structures. Due to the low dynamics of GNSS geometry, these criteria are quite tight and we found only 4-8 structures per day. However, if the particular structure was detected also for another GNSS satellite, this GNSS ratio was also computed (SWARM ratio is in this case the same).

Figure 8 presents the results of this comparison for 126 samples. Although the number of samples is low, they are quite 


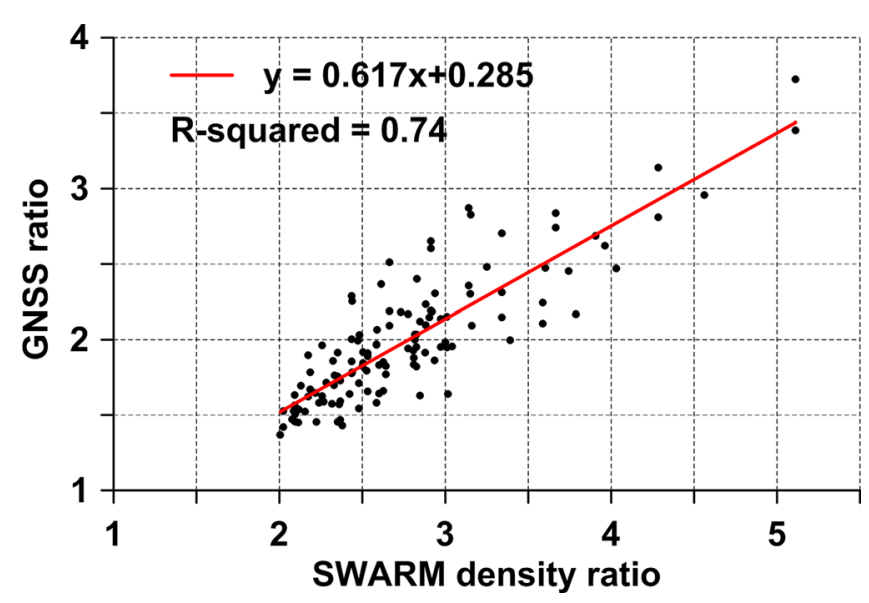

Fig. 8. The relationship between of SWARM density ratio and GNSS-derived ratio.

coincident. Based on this preliminary analysis it seems to be reasonable to set the minimal GNSS ratio for patch structure at the level of 1.5. For the stronger enhancement of density, GNSS ratio growths slower what is basically expected. On the other hand the number of such data is very low and detailed analysis of this dependency requires further tests. The observed discrepancies are probably related to temporal and spatial differences between points of observations as well as to a slant direction of GNSS data, which may lead to under- and overestimation of STEC values. Finally, considering STEC instead of VTEC in equation (4), the threshold of GNSS ratio can be approximated with 1.25 , what corresponds to elevation mask equal to $30^{\circ}$.

\section{Analysis of polar patch occurrence using the relative STEC}

According to Sections 3-5 the relative STEC enables identification of TOI/patches. Furthermore, analysing the temporal distribution of observations in the polar cap given in Figure 6d, it can be assumed that GNSS techniques allows the continuous detection of these structures at the North Pole. Thus, for transparent visualization their occurrence and STEC enhancement for all events, only the results from sector given in Figure 9 were used.

At this stage we decided to use arcs of the selected satellites only (the same for all stations). The criterion of selection was the number of samples within the sector given in Figure 9 (usually 3-5 at each epoch) and the observed structures. Such approach reduces the blurring of patches, related to the difference in signatures for particular satellites, and ensures that the derived time series are homogenous within the interval $1-2 \mathrm{~h}$ (typical period for each satellite). At the boundaries of these intervals the data from different arcs overlap each other. Please also note that the dawn-dusk extension of sector may result in practically undisturbed data for some satellites. In such case the applied selection automatically excludes the arcs with no signatures. As an indicator we used maximal relative STEC value at each epoch.

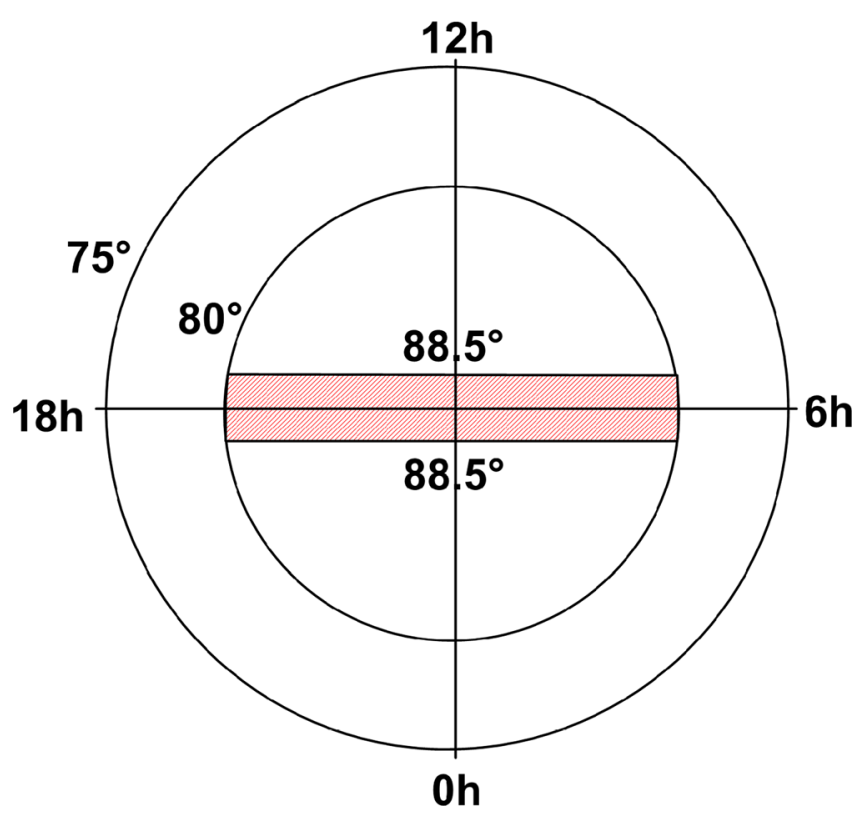

Fig. 9. Sector used for patch analysis.

Figure 10 summarizes the patch detection for all events. Apart from geomagnetic conditions in the top panels and relative STEC values (black line in the bottom panels), it demonstrates also 0.5 VTEC values at the north geomagnetic pole (solid red line) and VTEC on the dayside ionosphere - 12 MLT, $70^{\circ}$ of AACGM latitude (dashed red line). The first VTEC parameter defines the minimal enhancement for patch structure under the assumptions GNSS ratio $>1.5$, whereas the second one roughly corresponds to plasma density at the equatorward boundary of oval. Both VTEC values were taken from global ionosphere maps provided by ESOC. For clarification purpose the periods with structures are labelled with consecutive numbers.

Looking at the results for S1 event, given in Figure 10a, one can observe two periods of patch occurrence (denoted as \#1 and \#2) for southward IMF. The first sequence was detected near the pole at the peak of SYM-H index. These structures were the most intense patches in the entire analysed period ( $>20$ TECU) and began with an extreme one characterized with the period of propagation equal to $\sim 1.3 \mathrm{~h}$ (taking into account the second parameter it should be classified as TOI). The next, significantly weaker, sequence of patches (\#2) lines with another period of negative IMF Bz. The about 1-hour temporal shift between relative STEC values and IMF Bz is related to the response of the ionospheric convection pattern (e.g. Hairston \& Heelis, 1995) and time of plasma propagation on the dayside. The strong discrepancies between patch enhancements in periods \#1 and \#2 may resulted from opposite polarity of IMF By (Fig. 10a) as well as daily modulation of patch density (Sojka et al., 1994). The lack of structures between both periods cannot be fully explained due to the partly incomplete OMNI database. However, according to the results given in the next section, it seems to be related with strong variations of dayside oval boundary.

In Figure $10 \mathrm{~b}$ there are demonstrated the results for S2 event, covering two subsequent days of 8 and 9 March 
a)
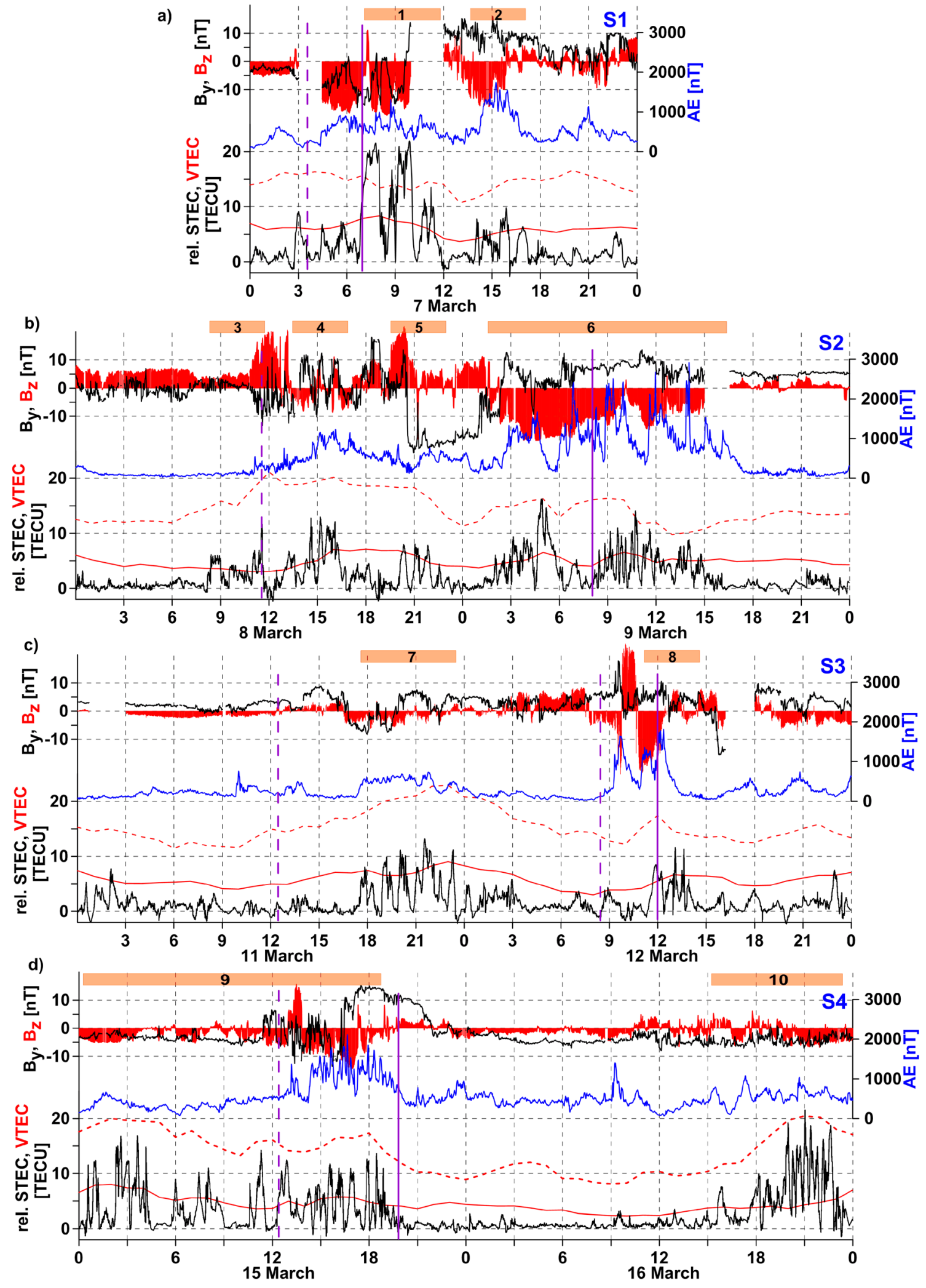

Fig. 10. The occurrence of polar patches during $\mathrm{S} 1-\mathrm{S} 4$ events $(\mathrm{a}-\mathrm{d})$ depicted with relative STEC values (black line), consecutive sequences of structures labelled with numbers. The solid red line corresponds to 0.5 VTEC at the North Pole, i.e. minimal STEC enhancement for patch structure. The dashed red line is the VTEC for dayside ionosphere (12 MLT, $70^{\circ}$ of AACGM latitude). Top panels present variations of geomagnetic indices. IP shocks and minima of SYM-H index for S1-S4 are marked with dashed and solid purple lines, respectively. 


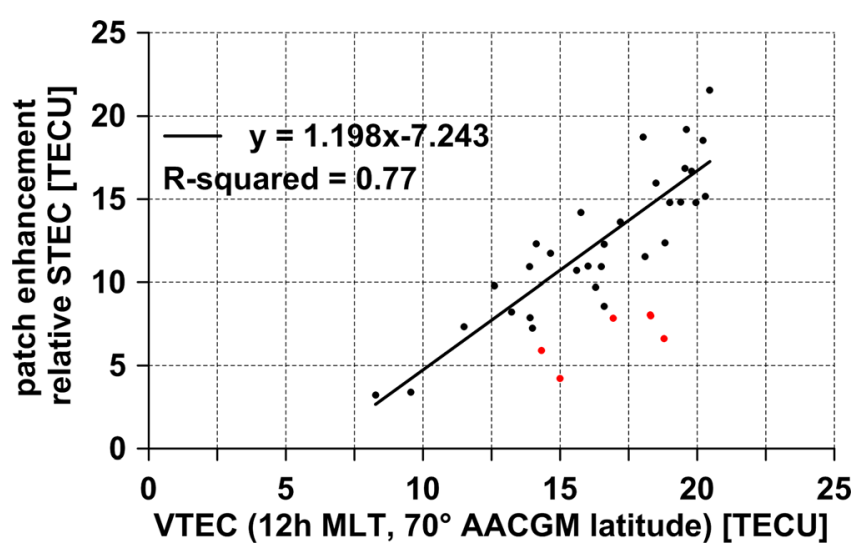

Fig. 11. The dependence of STEC patch enhancement on dayside VTEC. Black dots - results for 15-16 March and its linear approximation, red dots - structures observed for positive IMF Bz (8 March).

2012. Analysing the relative STEC values one can observe an extremely quiet ionosphere during a pre-storm period (00:00-8:00 UT). This low activity corresponds to northwardly oriented IMF and relatively low VTEC on the dayside ( 12 TECU). The first structures on 8 March (\#3) appeared in practically unchanged geomagnetic conditions, i.e. steady and moderate IMF Bz $>0$. Excluding the last signature, the patches did not exceed 6 TECU in STEC enhancement and, according to the Figure 10b, their occurrence lines with the growth of dayside VTEC. The last peak in relative STEC values observed at the end of period \#3 seems to be related to a transpolar arc, which occurrence between 10:30-12:00 UT was reported in Prikryl et al. (2015b). The next patches (\#4) appeared after north-south change of IMF Bz and thus, this case was basically similar to these observed for event $\mathrm{S} 1$. The much more interesting is another sequence of patches (\#5) detected for period of almost entirely northward IMF. Comparing these conditions and the quiet, initial period of northward IMF, one can observe an increasing of dayside VTEC by a factor of 1.5. Furthermore, the termination of ionospheric activity for period \#5 is also coincident with gradual depletion of VTEC. This suggests that the higher-density dayside plasma may participate in forming of patches. The structures observed in this period were generally weaker than for southwardly oriented cases. The second part of Figure 10b (9 March 2012) shows the conditions during the main phase of S2 event, as well as the initial recovery hours. As is evident the rapid change of IMF Bz led to the onset of the elongated period of patch activity, denoted as \#6. The derived relative STEC values seem to be modulated by AE variations, i.e. the lower-density patches or their lack are preceded by the depletions of this index at $\sim 5: 30$ and 11:00 UT, respectively. This is probably related with well-recognized dependence of equatorward oval boundary on AE (e.g. Xiong et al., 2014), which modulates the amount of plasma entering the polar cap.

The results for last two storms (Fig. 10c and d) clearly depict more frequent occurrence of patches during southwardly oriented IMF. The first structures denoted as \#7, which appeared after the first IP shock, correspond to the period of only slightly negative IMF Bz and a strongly enhanced VTEC on the dayside (>20 TECU). The comparison of the relative STEC and dayside
VTEC values in the next hours indicates a worse agreement between both parameters. However, in this case distribution of GNSS measurements was strongly unfavourable and covered the nightside ionosphere only. The similar pattern, with IMF $\mathrm{Bz}$ dependency, is observed for the next structures detected at the peak of SYM-H index (\#8). The results derived for the last storm (Fig. 10d) are noteworthy due to the relatively stable geomagnetic conditions and large number of structures. Excluding a few hours long interval following the IP shock, IMF Bz and By mostly varied between -5 and $0 \mathrm{nT}$ and the conditions can be treated as roughly homogenous. In such case the occurrence of patches during periods \#9 and \#10 is strongly coincident with two maxima of dayside VTEC. Furthermore, the depletion of this parameter during initial hours of recovery phase corresponds to period of an extremely quiet ionosphere. Figure 11 presents summary of results for $\mathrm{S} 4$ event and depicts the relation between enhancement of patches and dayside VTEC for southward moderate IMF. For the comparison purpose the figure includes also the patches observed for positive IMF Bz (on 8th March). In this second case the structures were generally weaker and occurred for high dayside density only. Due to the very low number of samples, the observed relationship needs further tests with larger dataset.

\section{Analysis of TEC fluctuation based on ROTI index}

Although TEC fluctuation maps are well-recognized source of information on auroral oval evolution, the high temporal resolution of such analyses is still restricted by the irregular distribution of permanent receivers (Fig. 6a). In order to overcome this limitation and investigate the short-term variations of day- and night-side oval, we proposed to utilize the approximate shape of this phenomenon. Knowing the spatial distribution of oval, it is possible to convert the measurements between different directions in MLT domain. In this work we used the model provided by Holzworth and Meng (1975), available at https://ccmc.gsfc. nasa.gov/pub/modelweb/ionospheric/auroral_oval/feldstein_ holzworth. Since this model involves only a $\overline{6}$-graduated scale and can be not enough accurate during storms, the conversion was performed with the following steps. Firstly, the preliminary equatorward boundaries of oval for four MLT sectors $(0 \pm 2 \mathrm{~h}$, $6 \pm 2 \mathrm{~h}, 12 \pm 2 \mathrm{~h}, 18 \pm 2 \mathrm{~h}$ ) were computed using real 15-minute observations. For this purpose mean values of ROTI calculated in 2-degree bands of AACGM were used. As an indicator of searched parameter we adopted the lowest latitude with average ROTI higher than 0.3 TECU/min. Such dataset, 4 or less (depending on distribution of observations), was subsequently applied to find the best-fitted model of oval. Treating it as the approximation of current ionospheric conditions, it was possible to recalculate AACGM latitude of ROTI observations from day- and night-side ionosphere to noon and midnight directions, respectively. Due to the still feasible discrepancies between dataset and model, the conversion covered data within the modelled oval and 3-degree adjacent bands. In specific, the observations located inside the oval were projected proportional to both its boundaries at specified MLT and target axis, whereas in the case of outer bands, it was done using differences between equatorward/poleward 

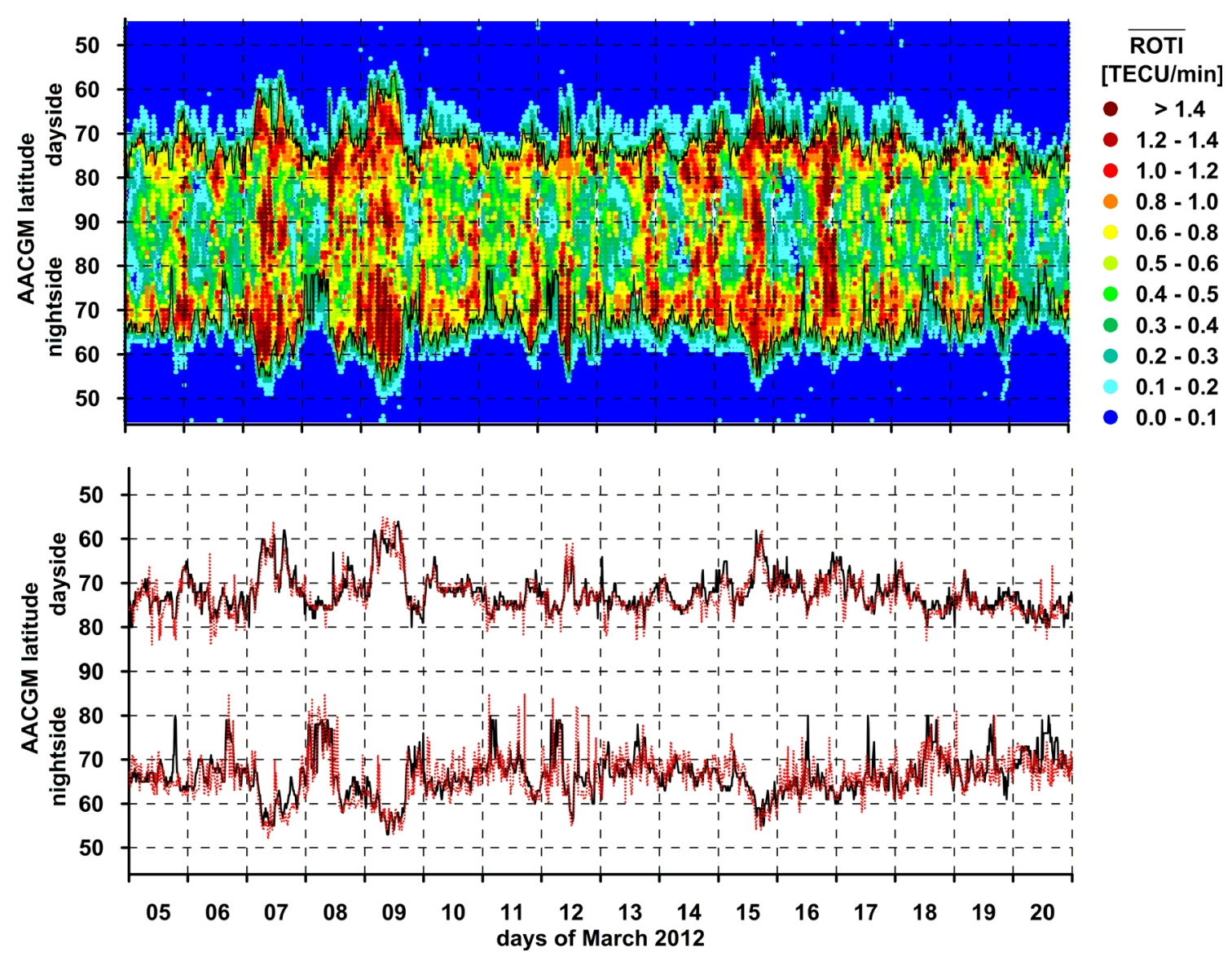

Fig. 12. The average ROTI values observed on both sides of ionosphere for entire analysed period: 5-20 March 2012 (top panel). Black lines correspond to outer oval boundary based on the assumption average ROTI $>0.3 \mathrm{TECU} / \mathrm{min}$. The bottom panel presents comparison of equatorward boundaries derived from GNSS (black solid line) and AMPERE datasets (red dotted line).

boundaries. Finally, we computed mean ROTI values in $15 \mathrm{~min}$ intervals for $2^{\circ}$ bands of AACGM latitude (shift between consecutive values equalled $1^{\circ}$ ).

Top panel of Figure 12 presents the summary of results for period 5-20 March. The first, clearly depicted effects are wellknown day/night asymmetry of oval and its expansion during geomagnetic storms. During quiet ionosphere the outer boundaries were located at $\sim 75^{\circ}$ and $67^{\circ}$ of AACGM latitude for sunlit and dark region, respectively. In such conditions the maximum of TEC fluctuation on both sides was at similar level reaching up to $\sim 1 \mathrm{TECU} / \mathrm{min}$. As it could be expected, the detailed investigations of poleward boundary are restricted by small and medium disturbances resulting from patch instability. This holds true even for undisturbed days. All these polar structures caused TEC fluctuation at the similar level as in the case of auroral oval. On the other hand this seems to confirm that under favourable conditions multi-station ROTI data can be used for TOI/patch detection (Cherniak et al., 2015).

The one of characteristic derived from Figure 12 is equatorward boundary of oval (depicted with black line) corresponding to the lowest latitude with average ROTI $>0.3 \mathrm{TECU} / \mathrm{min}$. In order to validate this GNSS-based parameter and consequently the applied conversion to noon-midnight axis, we used
10 min data of field aligned current (FAC) derived from AMPERE project (Active Magnetosphere and Planetary Electrodynamics Response Experiment - http://ampere.jhuapl.edu/). As an indicator of outer boundary we adopted the lowest latitude with absolute current density higher than $0.2 \mu \mathrm{A} / \mathrm{m}^{2}$ (Clausen et al., 2012), computed by averaging data from ranges $0 \pm 2 \mathrm{~h}$ and $12 \pm 2 \mathrm{~h}$ of MLT for two epochs nearest to mean ROTI time. This criterion was fulfilled at $97 \%$ and $78 \%$ epochs (dayside and nightside, respectively). In the opposite case, we applied the same threshold to maximal current density. The second condition is expected to be less stable, however, for our dataset the results are coincident.

The summary of equatorward boundaries derived from both techniques, given in the bottom panel of Figure 12, confirms their agreement. We did not observe any bias between both techniques. The correlation coefficients between the corresponding time series equal to 0.83 and 0.64 for dayside and nightside, respectively. The lower value in the latter case is a consequence of high variability of AMPERE results. Furthermore, the worse agreement on the nightside is also observed for periods with positive IMF Bz. It seems to be related to the low TEC fluctuation level in such conditions, which makes it difficult to assess the location of oval boundary. 

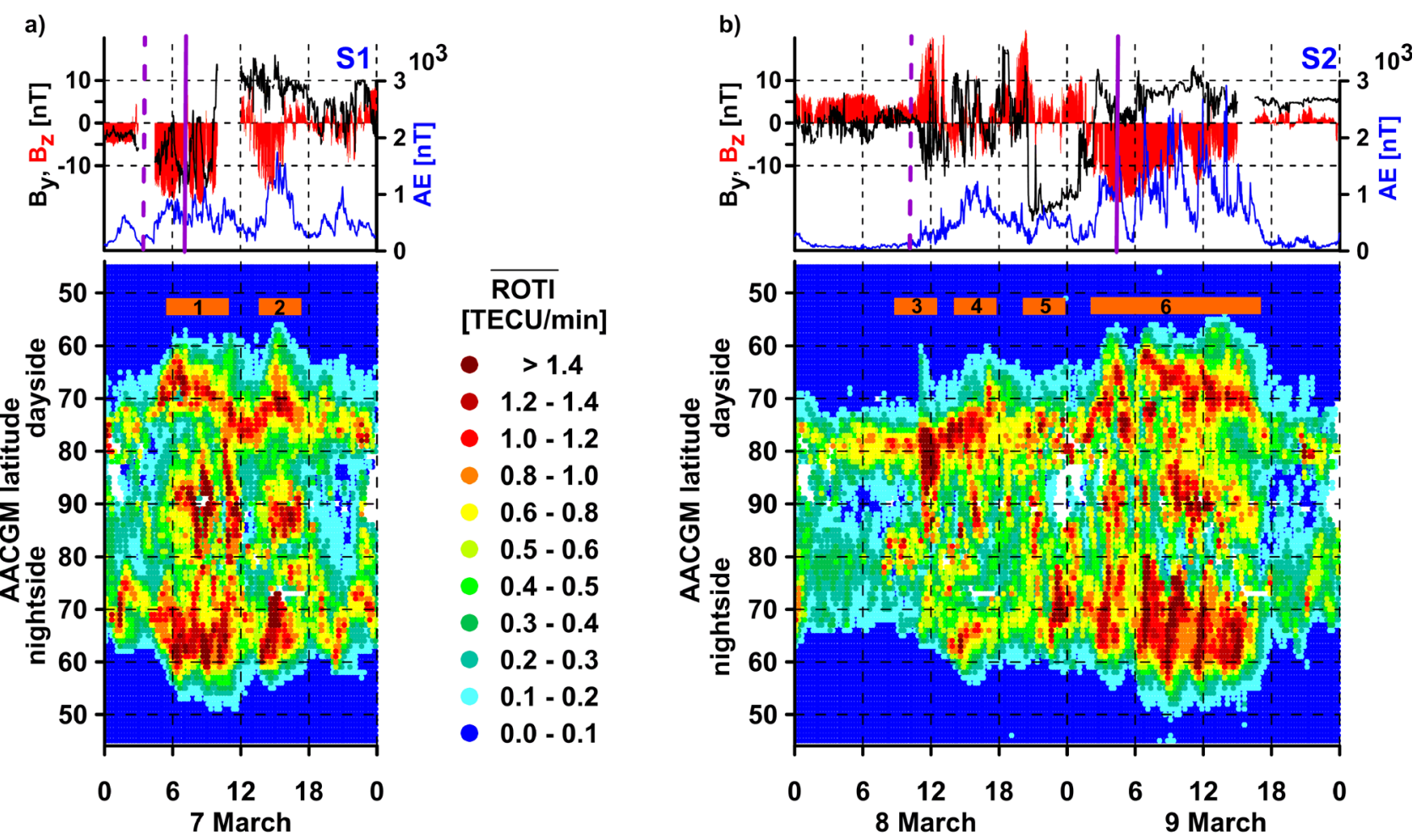

c)

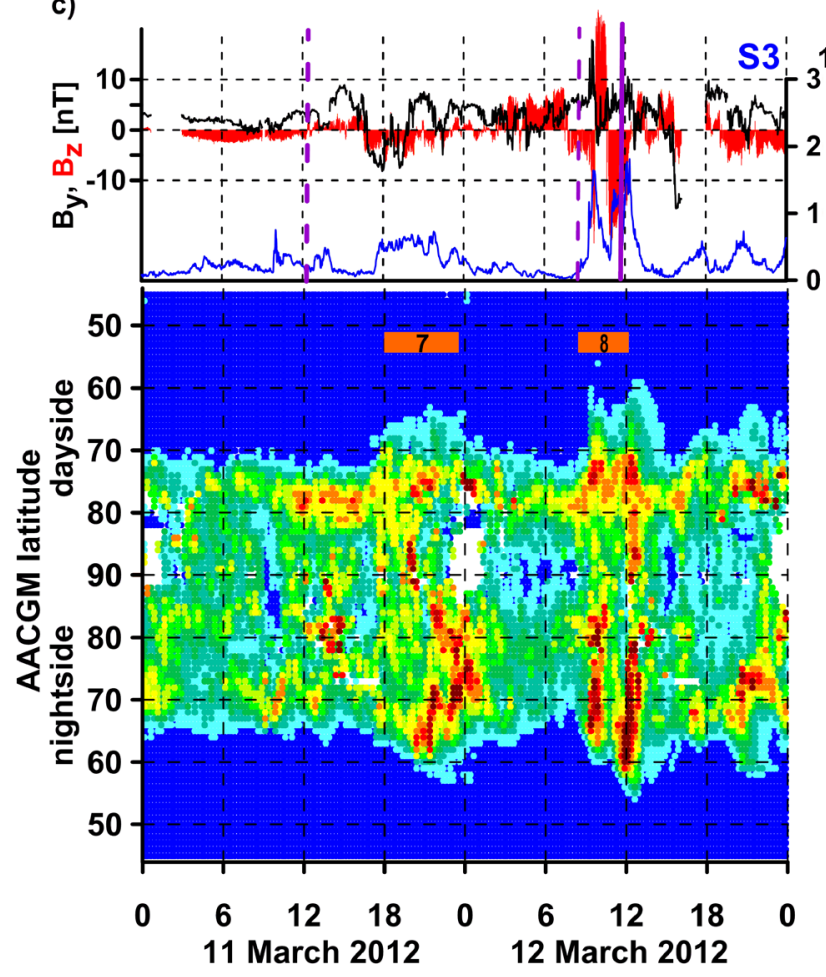

d)
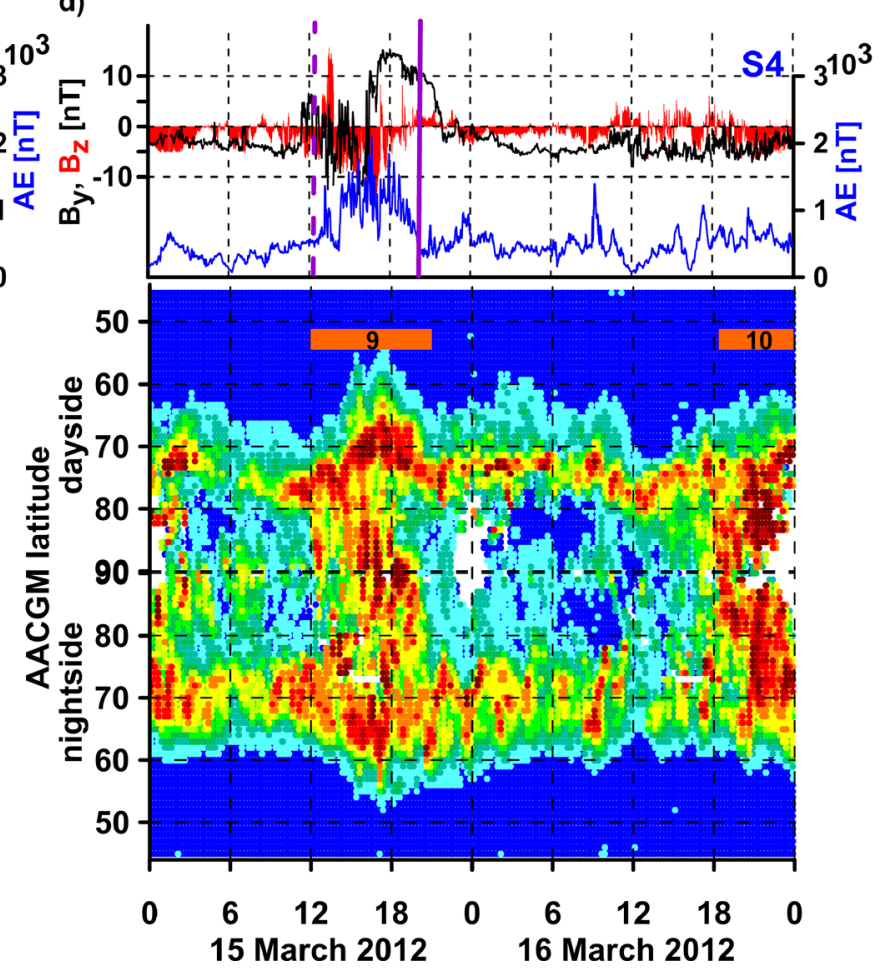

Fig. 13. The average ROTI values observed on both sides of ionosphere during events $\mathrm{S} 1-\mathrm{S} 4$ (a-d), consecutive periods with high TEC fluctuation are labelled with numbers. Top panels present variations of geomagnetic indices. IP shocks and minima of SYM-H index for S1-S4 are marked with dashed and solid purple lines, respectively.

Figure 13 presents the details of TEC fluctuation levels observed for S1-S4 events. It provides the information on the average ROTI values along noon-midnight axis (in the bottom panels) and corresponding geomagnetic conditions (in the top panels). The periods with high auroral activity are labelled with consecutive numbers. During S1 event (Fig. 13a) one can 
observe two main phases of the oval expansion related to the magnetic reconnection, denoted as (\#1) and (\#2). The onset of the first auroral activity was following the IP shock and corresponds to sudden increase of AE up to $\sim 500 \mathrm{nT}$. It resulted in a development of oval to $60^{\circ}$ and $55^{\circ}$ of AACGM latitude on day- and nightside, respectively. The second phase, also coincident with the enhancement of $\mathrm{AE}$ index, was characterized by the similar expansion of oval. During both periods an average TEC fluctuation reached up to $1.5 \mathrm{TECU} / \mathrm{min}$. The high ROTI values in the polar cap are related to patch propagation depicted in Figure 10a. Figure 13a provides also more detailed view of conditions between these periods. It demonstrates the mitigation of TEC fluctuation on the nightside, whereas on the sunlit part it is basically unchanged. In the second case one can also observe the poleward displacement of strong ionospheric variations to $75^{\circ}-78^{\circ}$ of latitude. This seems to be a consequence of northward IMF, partly demonstrated in OMNI data, and particle precipitation controlled by a lobe reconnection (Østgaard et al., 2003). Such conditions explain the lack of patches between periods \#1 and \#2 depicted in Figure 10a.

The details of auroral oval development for the second event are given in Figure 13b. As it was indicated in previous section this storm was preceded by several hours of northwardly oriented IMF, characterized by very low ionospheric activity. Analysing these results one can observe the moderate TEC fluctuation occurring at the dayside only $\left(76^{\circ}-79^{\circ}\right.$ of AACGM latitude). In the next hours ROTI values show a rapid growth of ionospheric variability to the level of $1.7 \mathrm{TECU} / \mathrm{min}$ (\#3). This effect seems to be related to the transpolar arc, which has been recently reported with scintillation and auroral image data by Prikryl et al. (2015b). Subsequently, the slow expansion of dayside oval corresponds to growth of AE index (\#4). It is worth noticing that the nightside ionosphere was in this case relatively quiet, i.e. the strong TEC fluctuation covered only a narrow band of latitudes. This may be connected with an occurrence of oval-aligned arc, since these phenomena were detected after north-south change of IMF polarity as well (Kullen et al., 2002).

The ionospheric conditions during another period of northward IMF (\#5) varied considerably from the previously described. In this case the moderate and strong TEC fluctuations were distributed in the entire area of high latitudes. Furthermore, the pattern observed in ROTI values suggests the occurrence of patches. This is coincident with the results of relative STEC (Fig. 10b). It is worth noticing that the signatures of patches in ROTI values were observed on the nightside as well. The results for the second day of S2 event (9 March) depict the dependence of TEC fluctuation intensity on auroral electrojet (\#6). Thus, analysing nightside ionosphere one can observe the enhancement of ROTI values (up to $2.0 \mathrm{TECU} / \mathrm{min}$ ) corresponding to the variations of $\mathrm{AE}$ index. Furthermore, each of such phases was followed by poleward shift of strong TEC fluctuations related to substorm development. The dayside TEC fluctuation was slightly weaker and smoothed in time domain. In this case we detected the gradual poleward shift of maximal ROTI values from $60^{\circ}$ to $72^{\circ}$.

The third storm was basically the weakest considering the intensity of TEC fluctuation. In this case one can distinguish two periods of enhanced auroral activity, denoted in Figure 13c as \#7 and \#8. The former, detectable mostly on the nightside, corresponds to phase of moderately negative IMF Bz after the

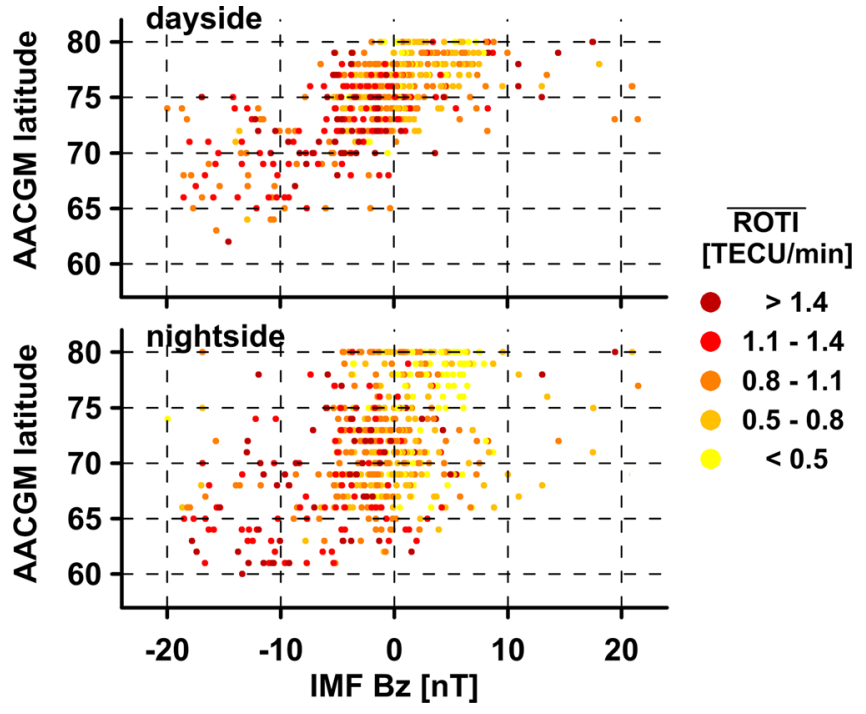

Fig. 14. The position of the maximal TEC fluctuation as a function of IMF Bz.

first IP shock. The period \#8 represents the ionospheric response during the main phase of S3 event. It depicts the dynamics of ionospheric conditions in relation to $\mathrm{IMF} \mathrm{Bz}$ and $\mathrm{AE}$ variations. Thus, two sharp peaks of the strong nightside TEC fluctuation (up to $1.5 \mathrm{TECU} / \mathrm{min}$ ) lined with southward IMF and high values of AE index. The northward IMF orientation between them was responsible for sudden drop of the ionospheric variability. The results for the dayside basically repeat this pattern with the difference for period with $\mathrm{Bz}>0$, where the poleward shift of TEC fluctuation was observed.

During S4 event IMF Bz was generally southward or oscillated around $0 \mathrm{nT}$ and thus, the moderate TEC fluctuation occurred practically continuous (Fig. 13d). Nevertheless, the particularly strong effects were observed for two periods. The first, connected with high auroral activity, was nearly coincident with the main phase of S4 (\#9). The second phase of intensive TEC fluctuation (\#10) resulted from the polar patch occurrence (Fig. 10d). In this case the enhancement in ROTI values were observed for auroral and Polar Regions, however, there was no expansion of oval. Furthermore, the intensity of patch-related TEC fluctuation was comparable with this for high auroral activity (\#9). Analysing the time between \#9 and \#10, corresponding to initial hours of recovery phase, one can observe the moderate TEC fluctuation. This effect seems to follow weak $\mathrm{AE}$ variations on the nightside, whereas on the dayside it is practically unchanged and occurs at $\sim 72^{\circ}-73^{\circ}$ of AACGM latitude.

The presented above results indicated the latitudinal dependence of the auroral TEC fluctuation on geomagnetic conditions. Thus, Figure 14 provides the comparison of the maximal ROTI location with IMF Bz polarity (in this second case we also used $15 \mathrm{~min}$ average). In order to exclude the patch-related effects, the selection of ROTI involved the latitudes below $80^{\circ}$. The presented summary depicts the dependence between orientation of IMF Bz and the position of maximal fluctuation as well as its intensity. As expected, the expansion oval for southward IMF implicates the equatorward shift of strong TEC 
fluctuations. Analysing the opposite geomagnetic conditions the maximal ROTI values occurred mainly above $75^{\circ}$ of AACGM latitude. However, the dayside TEC fluctuation for positive IMF Bz was generally stronger than this observed on the nightside ( $\sim .7$ and $\sim 0.4 \mathrm{TECU} / \mathrm{min}$, respectively). These results agree with statistical study of scintillation provided by Prikryl et al. (2015a).

\section{Summary and conclusions}

This contribution demonstrated the analysis of the polar patch occurrence and auroral activity during the sequence of geomagnetic storms in March 2012. The detection of the patches was realized with the new algorithm of $L_{4}$ data processing providing the relative STEC values. The novel approach assumes the extraction of ionospheric signatures with iteratively fitted 4-order polynomial corresponding to the background STEC variations. The cross-evaluation of relative STEC and ROTI values showed that the new indicator ensures more comprehensive view of ionospheric conditions, which is particularly valuable for polar patches. The proposed approach can be also considered as a promising alternative for detailed investigations of other high-latitude structures. Moreover, the results of relative STEC values were preliminary validated with SWARM PCP project dataset, what confirmed the applicability of the new indicator.

The results on patch detection during sequence of geomagnetic storms are fully compatible with the current knowledge on this topic. They confirm that these structures are very frequent and occur predominantly for southwardly oriented IMF. In the analysed period the patches were detected after each onset of southward IMF during strong and moderate geomagnetic activity. In such cases the line-of-sight enhancement was mostly in range 10-20 TECU. For the opposite IMF polarity the polar structures were significantly less frequent and did not exceed 10 TECU. Furthermore, we have noticed that STEC enhancement of detected patches varied according to the dayside VTEC derived from global ionosphere maps. As a result the integration of both parameters can be useful to explain the strength of patch activity for different geomagnetic conditions.

The second part of investigations was aimed at characterization of the auroral oval activity. We depicted the rapid expansion of oval during geomagnetic storms, which occurred with the onset of southward IMF polarity and rapid enhancement of auroral electrojet. For the analysed events the equatorward boundaries of oval were detected at $\sim 60^{\circ}$ and $\sim 55^{\circ}$ of AACGM latitude on day- and nightside, respectively. In addition, the results demonstrated the dependence of strong TEC fluctuation position as well as its intensity on IMF Bz. In the case of northwardly oriented IMF, we observed the poleward shift of maximal ROTI values. For such conditions the nightside ionosphere was relatively quiet, whereas the sunlit part was characterized by moderate TEC fluctuation observed at $75^{\circ}-80^{\circ}$ of AACGM latitude. The results of TEC fluctuation confirmed that ROTI can be used for patch detection, but its efficiency strongly depends on signature of particular structure.

Acknowledgements. This work was supported by the National Science Centre, Poland: project No. 2016/23/D/ST10/01546. The authors are grateful for GNSS data and products provided by IGS/EPN, ESOC and UNAVCO. We acknowledge the use of NASA/GSFC's Space Physics Data Facility's OMNIWeb service and OMNI data as well as Polar Cap Project data founded by ESA and realized by Department of Physics, University of Oslo. We thank the AMPERE Science Center and team for providing the Iridium-derived data products. The auroral model, created by R.H. Holzworth and C.I. Meng, was provided by the Community Coordinated Modeling Center (CCMC). We also acknowledge the time and effort devoted by the editor and reviewers on improving the quality of this work. The editor thanks two anonymous referees for their assistance in evaluating this paper.

\section{References}

Astafyeva E, Yasyukevich Y, Maksikov A, Zhivetiev I. 2014. Geomagnetic storms, super-storms, and their impacts on GPSbased navigation systems. Space Weather 12: 508-525. DOI: 10.1002/2014SW001072.

Banville S, Sieradzki R, Hoque M, Wezka K, Hadas T. 2017. On the estimation of higher-order ionospheric effects in precise point positioning. GPS Solut 21(4): 1817-1828. DOI: 10.1007/s10291017-0655-0.

Belehaki A, Kutiev I, Marinov P, Tsagouri I, Koutroumbas K, Elias P. 2017. Ionospheric electron density perturbations during the 7-10 March 2012 geomagnetic storm period. Adv Space Res 59(4): 1041-1056. DOI: 10.1016/j.asr.2016.11.031.

Bowline MD, Sojka JJ, Schunk RW. 1996. Relationship of theoretical patch climatology to polar cap patch observations. Radio Sci 31: 635-644. DOI: 10.1029/96RS00236.

Branzanti M, Colosimo G, Crespi M, Mazzoni A. 2013. GPS nearreal-time coseismic displacements for the Great Tohoku-Oki Earthquake. IEEE Geosci Remote Sens Lett 10(2): 372-376. DOI: 10.1109/LGRS.2012.2207704.

Burston R, Mitchell C, Astin I. 2016. Polar cap plasma patch primary linear instability growth rates compared. J Geophys Res Space Phys 121: 3439-3451. DOI: 10.1002/2015JA021895.

Carlson HC. 2012. Sharpening our thinking about polar cap ionospheric patch morphology, research, and mitigation techniques. Radio Sci 47: RSOL21. DOI: 10.1029/2011RS004946.

Cherniak I, Zakharenkova I, Redmon R. 2015. Dynamics of the highlatitude ionospheric irregularities during the March 17, 2015 St. Patrick's Day storm: ground-based GPS measurements. Space Weather 13: 585-597. DOI: 10.1002/2015SW001237.

Cherniak I, Zakharenkova I. 2017. New advantages of the combined GPS and GLONASS observations for high-latitude ionospheric irregularities monitoring: case study of June 2015 geomagnetic storm. Earth Planets Space 69. DOI:10.1186/s40623-017-0652-0.

Clausen LBN, Baker JBH, Ruohoniemi JM, Milan SE, Anderson BJ. 2012. Dynamics of the region 1 Birkeland current oval derived from the Active Magnetosphere and Planetary Electrodynamics Response Experiment (AMPERE). J Geophys Res 117: A06233. DOI: 10.1029/2012JA017666.

Crowley G. 1996. Critical review of ionospheric patches and blobs. In: Review of Radio Science 1993-1996, Stone WR (Ed.), Oxford University Press, New York. pp. 619-648.

Durgonics T, Komjathy A, Verkhoglyadova O, Shume EB, Benzon HH, Mannucci AJ, Butala MD, Høeg P, Langley RB. 2017. Multiinstrument observations of a geomagnetic storm and its effects on the Arctic ionosphere: A case study of the 19 February 2014 storm. Radio Sci 52: 146-165. DOI: 10.1002/ 2016RS006106. 
Feltens J. 2007. Development of a new three-dimensional mathematical ionosphere model at European Space Agency/European Space Operations Centre. Space Weather 5: S12002. DOI: 10.1029/2006SW000294.

Forte B. 2007. On the relationship between the geometrical control of scintillation indices and the data detrending problems observed at high latitudes. Ann Geophys 50: 699-706. DOI: 10.4401/ag-3051.

Grant IF, MacDougall JW, Ruohoniemi JM, Bristow WA, Sofko GJ, Koehler JA, Danskin D, Andre D. 1995. Comparison of plasma flow velocities determined by the ionosonde Doppler drift technique, SuperDARN radars, and patch motion. Radio Sci 30: 1537-1549.

Gopalswamy N, Tsurutani B, Yan Y. 2015. Short-term variability of the Sun-Earth system: an overview of progress made during the CAWSES II period. Prog Earth Planet Sci 2: 13. DOI: 10.1186/ s40645-015-0043-8.

Hairston MR, Heelis RA. 1995. Response time of the polar ionospheric convection pattern to changes in the north-south direction of the IMF. Geophys Res Lett 22: 631-634.

Hernández-Pajares M, Miguel J, Sanz J, Aragón-Àngel À, GarciaRigo A, Salazar D, Escudero M. 2011. The ionosphere: effects, GPS modeling and the benefits for space geodetic techniques. $J$ Geod 85(12): 887-907. DOI: 10.1007/s00190-011-0508-5.

Holzworth RH, Meng C-I. 1975. Mathematical Representation of the Auroral Oval. Geophys Res Lett 2: 377-380.

Horvath I, Lovell BC. 2014. Large plasma density enhancements occurring in the northern polar region during the 6 April 2000 superstorm. J Geophys Res Space Phys 119: 4805-4818. DOI: 10.1002/2014JA019917.

Hosokawa K, Taguchi S, Ogawa Y. 2016. Edge of polar cap patches. J Geophys Res Space Phys 121: 3410-3420. DOI: 10.1002/ 2015JA021960.

Jakowski N, Mayer C, Hoque MM, Wilken V. 2011. Total electron content models and their use in ionosphere monitoring. Radio Sci 46: RS0D18. DOI: 10.1029/2010RS004620.

Jayachandran PT, Langley RB, MacDougall JW, Mushini SC, Pokhotelov D, et al. 2009. The Canadian high arctic ionospheric network (CHAIN). Radio Sci 44: RSOA03. DOI: 10.1029/ 2008RS004046.

Jin Y, Moen JI, Miloch WJ. 2014. GPS scintillation effects associated with polar cap patches and substorm auroral activity: direct comparison. J Space Weather Space Clim 4: A23. DOI: $10.1051 /$ swsc/2014019.

Kitamura N, Nishimura Y, Chandler MO, Moore TE, Terada N, Ono T, Shinbori A, Kumamoto A. 2012. Storm-time electron density enhancement in the cleft ion fountain. J Geophys Res 117: A11212. DOI: 10.1029/2012JA017900.

Komjathy A, Sparks L, Wilson BD, Mannucci AJ. 2005. Automated daily processing of more than 1000 ground-based GPS receivers for studying intense ionospheric storms. Radio Sci 40: RS6006. DOI: $10.1029 / 2005 R S 003279$.

Krankowski A, Shagimuratov II, Baran LW, Epishov II, Tepenitzyna NJ. 2006. The occurrence of polar cap patches in TEC fluctuation using GPS measurements. Adv Space Res 38(11): 2601-2609. DOI: $10.1016 /$ j.asr.2005.12.006.

Kullen A, Brittnacher M, Cumnock JA, Blomberg LG. 2002. Solar wind dependence of the occurrence and motion of polar auroral arcs: A statistical study. J Geophys Res 107: A11. DOI: 10.1029/ 2002JA009245.

Li Z, Yuan Y, Wang N, Hernandez-Pajares M, Huo X. 2015. SHPTS: towards a new method for generating precise global ionospheric TEC map based on spherical harmonic and generalized trigonometric series functions. J Geod 89: 331-345. DOI: 10.1007/s00190-014-0778-9.
Li G, Ning B, Ren Z, Hu L. 2010. Statistics of GPS ionospheric scintillation and irregularities over polar regions at solar minimum. GPS Solut 14. DOI: 10.1007/s10291-009-0156-x.

Liu J, Chen R, Kuusniemi H, Wang Z, Zhang H, Yang J. 2010. A Preliminary study on mapping the regional ionospheric TEC using a spherical cap harmonic model in high latitudes and the arctic region. J Global Positioning Syst 9: 22-32. DOI: 10.5081/ jgps.9.1.22.

Liu Z. 2011. A new automated cycle slip detection and repair method for a single dual-frequency GPS receiver. J Geod 85(3): 171-183. DOI: 10.1007/s00190-010-0426-y.

Mitchell CN, Alfonsi L, De Franceschi G, Lester M, Romano V, Wernik AW. 2005. GPS TEC and scintillation measurements from the polar ionosphere during the October 2003 storm. Geophys Res Lett 32(12): L12S03. DOI: 10.1029/2004GL021644.

Ning Y, Tang J. 2018. Study of ionospheric disturbances over the China mid- and low-latitude region with GPS observations. Ann Geophys 36: 81-89. DOI: 10.5194/angeo-36-81-2018.

Noja M, Stolle C, Park J, Lbhr H. 2013. Long-term analysis of ionospheric polar patches based on CHAMP TEC data. Radio Sci 48(3): 289-301. DOI: 10.1002/rds.20033.

Østgaard N, Detrick DL, Rosenberg TJ, Vondrak RR, Frey HU, Mende SB, Hland S, Stadsnes J. 2003. High-latitude dayside energetic precipitation and IMF Bz rotations. J Geophys Res 108: 8013. DOI: 10.1029/2002JA009350.

Park J, Helmboldt J, Grejner-Brzezinska DA, von Frese RBR, Wilson TL. 2013. Ionospheric observations of underground nuclear explosions (UNE) using GPS and the very large array. Radio Sci 48: 463-469. DOI: 10.1002/rds.20053.

Paziewski J. 2015. Precise GNSS single epoch positioning with multiple receiver configuration for medium-length baselines: methodology and performance analysis. Meas Sci Technol 26(3): 035002. DOI: 10.1088/0957-0233/26/3/035002.

Pi X, Mannucci AJ, Lindqwister UJ, Ho CM. 1997. Monitoring of global ionospheric irregularities using the worldwide GPS network. Geophys Res Lett 24. DOI: 10.1029/97GL02273.

Pi X, Mannucci AJ, Valant-Spaight B, Bar-Sever Y, Romans LJ, Skone S, Sparks L, Hall Martin G. 2013. Observations of global and regional ionospheric irregularities and scintillation using GNSS tracking networks, Proceedings of the ION 2013 Pacific PNT Meeting, Honolulu, Hawaii.

Prikryl P, Jayachandran PT, Mushini SC, Richardson IG. 2014. High-latitude GPS phase scintillation and cycle slips during highspeed solar wind streams and interplanetary coronal mass ejections: a superposed epoch analysis. Earth Planets Space 66: 62. DOI: 10.1186/1880-5981-66-62.

Prikryl P, Jayachandran PT, Chadwick R, Kelly TD. 2015a. Climatology of GPS phase scintillation at northern high latitudes for the period from 2008 to 2013. Ann Geophys 33: 531-545. DOI: 10.5194/angeo-33-531-2015.

Prikryl P, Ghoddousi-Fard R, Thomas EG, Ruohoniemi JM, Shepherd SG, et al. 2015b. GPS phase scintillation at high latitudes during geomagnetic storms of 7-17 March 2012 - part 1: the North American sector. Ann Geophys 33: 637-656. DOI: 10.5194/angeo-33-637-2015.

Ren X, Zhang X, Xie W, Zhang K, Yuan Y, Li X. 2016. Global ionospheric modelling using multi-GNSS: BeiDou, Galileo, GLONASS and GPS. Sci Rep 6: 33499. DOI: 10.1038/srep33499.

Rideout W, Coster A. 2006. Automated GPS processing for global total electron content data. GPS Solut 10(3): 219-228. DOI: 10.1007/s10291-006-0029-5.

Ryu K, Parrot M, Kim SG, Jeong KS, Chae JS, Pulinets S, Oyama K-I. 2014. Suspected seismo-ionospheric coupling 
observed by satellite measurements and GPS TEC related to the M7.9 Wenchuan earthquake of 12 May 2008. J Geophys Res Space Phys 119: 10305-10323. DOI: 10.1002/2014JA020613.

Shepherd SG. 2014. Altitude-adjusted corrected geomagnetic coordinates: Definition and functional approximations. J Geophys Res Space Phys 119: 7501-7521. DOI: 10.1002/2014JA020264.

Sieradzki R, Cherniak Iu, Krankowski A. 2013. Near-real time monitoring of the TEC fluctuations over the northern hemisphere using GNSS permanent networks. Adv Space Res 52(3): 391-402. DOI: $10.1016 /$ j.asr.2013.03.036.

Sieradzki R. 2015. An analysis of selected aspects of irregularities oval monitoring using GNSS observations. J Atmos Sol Terr Phys 129: 87-98. DOI: 10.1016/j.jastp.2015.04.017.

Sieradzki R, Paziewski J. 2016. Study on reliable GNSS positioning with intense TEC fluctuations at high latitudes. GPS Solut 20(3): 553-563. DOI: 10.1007/s10291-015-0466-0.

Sojka JJ, Bowline MD, Schunk RW. 1994. Patches in the polar-cap ionosphere: UT and seasonal dependence. J Geophys Res 99: 14959-14970.

Sojka JJ, Subramanium MV, Zhu L, Schunk RW. 1998. Gradientdrift instability growth rates from global scale modeling of the polar ionosphere. Radio Sci 33(6): 1915-1928.

Spicher A, Clausen LBN, Miloch WJ, Lofstad V, Jin Y, Moen JI. 2017. Interhemispheric study of polar cap patch occurrence based on Swarm in situ data. J Geophys Res Space Phys 122: 3837-3851. DOI: 10.1002/2016JA023750.

Van der Meeren C, Oksavik K, Lorentzen D, Moen JI, Romano V. 2014. GPS scintillation and irregularities at the front of an ionization tongue in the nightside polar ionosphere. J Geophys Res Space Phys 119: 8624-8636. DOI: 10.1002/2014JA020114.

Verkhoglyadova OP, Tsurutani BT, Mannucci AJ, Mlynczak MG, Hunt LA, Paxton LJ. 2014. Ionospheric TEC, thermospheric cooling and $\Sigma\left[\mathrm{O} / \mathrm{N}_{2}\right]$ compositional changes during the 6-17 March 2012 magnetic storm interval (CAWSES II). J Atmos Sol Terr Phys 115-116: 41-51. DOI: 10.1016/j.jastp.2013. 11.009.

Wautelet G, Warnant R. 2014. Climatological study of ionospheric irregularities over the European mid-latitude sector with GPS. $J$ Geod 88(3): 223-240. DOI: 10.1007/s00190-013-0678-4.

Wilgan K, Rohm W, Bosy J. 2015. Multi-observation meteorological and GNSS data comparison with numerical weather prediction model. Atmos Res 156: 29-42. DOI: 10.1016/j.atmosres.2014.12. 011.

Tsagouri I, Belehaki A. 2015. Ionospheric forecasts for the European region for space weather applications. J Space Weather Space Clim 5: A9. DOI: 10.1051/swsc/2015010.

Tsurutani BT, Echer E, Shibata K, Verkhoglyadova OP, Mannucci AJ, Gonzalez WD, Kozyra JU, Paetzold M. 2014. The interplanetary causes of geomagnetic activity during the 7-17 March 2012 interval: a CAWSES II overview. J Space Weather Space Clim 4: A02. DOI: $10.1051 / \mathrm{swsc} / 2013056$.

Xiong C, Lühr H, Wang H, Johnsen MG. 2014. Determining the boundaries of the auroral oval from CHAMP field aligned current signatures - Part 1. Ann Geophys 32: 609-622. DOI: 10.5194/ angeo-32-609-2014.

Cite this article as: Sieradzki R \& Paziewski J 2019. GNSS-based analysis of high latitude ionospheric response on a sequence of geomagnetic storms performed with ROTI and a new relative STEC indicator. J. Space Weather Space Clim. 9, A5. 